\title{
Room-level ventilation in schools and universities
}

\author{
V. Faye McNeill ${ }^{\text {a,b, }}$, Richard Corsi ${ }^{\text {c }}$, J. Alex Huffman ${ }^{\mathrm{d}}$, Cathleen King ${ }^{\mathrm{e}}$, Robert Klein ${ }^{\mathrm{f}, \mathrm{g}}$, \\ Michael Lamore $^{\mathrm{h}}$, Do Young Maeng ${ }^{\mathrm{a}}$, Shelly L. Miller ${ }^{\mathrm{i}}$, Nga Lee $\mathrm{Ng}^{\mathrm{j}, \mathrm{k}, 1}$, Paula Olsiewski ${ }^{\mathrm{m}}$, \\ Krystal J. Godri Pollitt ${ }^{\mathrm{n}, \mathrm{o}}$, Rachel Segalman ${ }^{\mathrm{p}, \mathrm{q}}$, Alex Sessions ${ }^{\mathrm{r}}$, Todd Squires ${ }^{\mathrm{p}}$, \\ Sabrina Westgate ${ }^{\mathrm{j}}$
}

${ }^{a}$ Department of Chemical Engineering, Columbia University, New York, NY, 10027, USA

b Department of Earth and Environmental Sciences, Columbia University, New York, NY, 10027, USA

${ }^{\mathrm{c}}$ College of Engineering, University of California, Davis, CA, 95616, USA

${ }^{\mathrm{d}}$ Department of Chemistry and Biochemistry, University of Denver, Denver, CO, 80208, USA

${ }^{\mathrm{e}}$ Environmental Health and Safety, Yale University, New Haven, CT, 06520, USA

${ }^{\mathrm{f}}$ Occupational Health \& Environmental Medicine, Yale School of Medicine, New Haven, CT, 06520, USA

${ }^{\mathrm{g}}$ Coastal Safety, LLC, Clinton, CT, 06413, USA

${ }^{\mathrm{h}}$ Facilities Utilities and Engineering, Yale University, New Haven, CT, 06520, USA

${ }^{i}$ Department of Mechanical Engineering, University of Colorado, Boulder, Boulder, CO, 80309, USA

${ }^{\mathrm{j} S c h o o l}$ of Chemical and Biomolecular Engineering, Georgia Institute of Technology, Atlanta, GA, 30332, USA

${ }^{\mathrm{k}}$ School of Earth and Atmospheric Sciences, Georgia Institute of Technology, Atlanta, GA, 30332, USA

${ }^{1}$ School of Civil and Environmental Engineering, Georgia Institute of Technology, Atlanta, GA, 30332, USA

${ }^{\mathrm{m}}$ Center for Health Security, Johns Hopkins University, Baltimore, MD, 21202, USA

${ }^{\mathrm{n}}$ Department of Environmental Health Sciences, Yale School of Public Health, New Haven, CT, 06520, USA

${ }^{\circ}$ Department of Chemical and Environmental Engineering, Yale School of Engineering and Applied Science, New Haven, CT, 06511, USA

${ }^{\mathrm{p}}$ Department of Chemical Engineering, University of California, Santa Barbara, Santa Barbara, CA, 93106, USA

${ }^{\mathrm{q}}$ Department of Materials, University of California, Santa Barbara, Santa Barbara, CA, 93106, USA

${ }^{\mathrm{r}}$ Department of Geology and Planetary Sciences, California Institute of Technology, Pasadena, CA, 91125, USA

\section{A R T I C L E I N F O}

\section{Keywords:}

Ventilation

HVAC

Indoor air

Schools

Sensors

\begin{abstract}
A B S T R A C T
Ventilation is of primary concern for maintaining healthy indoor air quality and reducing the spread of airborne infectious disease, including COVID-19. In addition to building-level guidelines, increased attention is being placed on room-level ventilation. However, for many universities and schools, ventilation data on a room-byroom basis are not available for classrooms and other key spaces. We present an overview of approaches for measuring ventilation along with their advantages and disadvantages. We also present data from recent case studies for a variety of institutions across the United States, with various building ages, types, locations, and climates, highlighting their commonalities and differences, and examples of the use of this data to support decision making.
\end{abstract}

\section{Introduction}

Adequate ventilation with air free of harmful air pollutants is essential to maintaining a healthy indoor environment. In modern buildings, particularly in the U.S., this is usually accomplished by providing indoor spaces with a combination of outside and recirculated, conditioned, and filtered indoor air via a mechanical heating, ventilating, and air conditioning (HVAC) system. Although critical discussions of ventilation are usually focused on buildings with mechanical
HVAC, in many parts of the U.S. it is common for schools and university buildings to have only natural ventilation, which means ventilating via passive flow of outdoor air through windows, doors, and other openings. Natural ventilation is typically encountered in older buildings in the Northeast or in more temperate climates in the West. The ventilation design standard of the American Society of Heating, Refrigerating and Air Conditioning Engineers (ASHRAE) for education-related buildings ranges from $4.3 \mathrm{~L} \mathrm{~s}^{-1}$ person ${ }^{-1}$ of outdoor air for a lecture classroom to $8.6 \mathrm{~L} \mathrm{~s}^{-1}$ person $^{-1}$ for a science laboratory (ASHRAE 2019). Many

\footnotetext{
* Corresponding author. Department of Chemical Engineering, Columbia University, New York, NY, 10027, USA.

E-mail address: vfm2103@columbia.edu (V.F. McNeill).
} 
schools and universities in the U.S. do not meet this minimum standard (Corsi et al. 2021). Inadequate ventilation may result from: malfunctioning (or improperly configured or scheduled) air handling equipment, excessive air recirculation, inadequate natural ventilation, or simply by design to save on energy costs associated with heating or cooling.

Outbreaks of COVID-19, influenza, and other infectious diseases have been connected to inhalation of virus-laden respiratory aerosol in inadequately ventilated indoor spaces (Li et al., 2007; Miller et al., 2021, Greenhalgh et al. 2021; Corsi et al. 2021). Ventilation has well-documented benefits for reducing airborne infectious disease transmission, as well as other negative health and education outcomes (Fisk 2017; Wargocki et al., 2020, Corsi et al. 2021). Masking, improved ventilation, reduced occupancy, physical distancing, and other efforts to mitigate the spread of COVID-19 in the U.S. during the 2020-2021 flu season also led to dramatic reductions in other airborne illnesses such as influenza (Centers for Disease Control and Prevention, 2021).

In the wake of COVID-19 pandemic shutdowns, safe reopening of schools and universities for in-person instruction, and sustainable maintenance of safe conditions, has become an international priority. Since inhalation of respiratory aerosols containing infectious material is a key route of transmission for SARS-CoV-2 and other airborne pathogens (Greenhalgh et al. 2021), gathering of students and educators in school facilities with insufficient ventilation poses a public health risk. Since aerosol transmission is significant at both short- and room-scale distance, ventilation and filtration, along with distancing and mask wearing, are important components of layered risk reduction (Corsi et al. 2021). A correlation between improvements in ventilation and air filtration in schools and lower rates of COVID-19 incidence has been shown (Gettings et al., 2021).

In addition to building-level guidelines, e.g. that HVAC filters should be upgraded, outdoor air dampers should be opened entirely when weather permits, and demand-control ventilation should be disabled (ASHRAE 2020), increased attention is being placed on room-level ventilation and air cleaning. The Harvard Schools for Health group (Jones et al., 2020) and others (Corsi et al. 2021; Levinson et al., 2021) recommend classrooms meet a minimum of 3 outdoor-air supplied air changes per hour at standard occupancy and room sizes, and that this should be augmented with air cleaning (i.e., filtration or ozone-free upper-room germicidal ultraviolet light) for a total of 4-6 air changes per hour of outdoor plus filtered air. These recommendations are consistent with the minimum ventilation rates recommended by ASHRAE (ASHRAE 2019). In spaces with known ventilation issues, steps may be taken to increase the fraction of outdoor air that is supplied, improve the filtration efficiency of the recirculated air, or provide filtration on a room level. However, there is an overall lack of room-level ventilation data in educational spaces in the U.S. that would allow such planning. There are a number of reasons for this data gap, including that, while recommended guidelines exist for room-level ventilation (ASHRAE 2019), in many locations strict requirements only exist for special room types such as wet-chemical laboratories and auditoriums, or for buildings with special certification (U.S. Green Buildings Council, 2019). Room-level ventilation can be difficult to quantify as it can fluctuate with weather, season, room occupancy, etc. (Turner et al., 2012; Persily 2016; Korsavi et al., 2020). Moreover, conventional ventilation metrics and codes were designed to address different risks than those posed by infectious diseases. In particular, standard ventilation codes ensure enough fresh air is supplied to flush the exhalation and other bio-effluents of a specified number of occupants, generally assumed to be identical in their emissions and respiratory intake. Mitigating the spread of infectious disease, however, introduces an additional demand - to flush a room's air quickly enough to reduce the risk of occupants inhaling airborne pathogens generated by even one infected individual.

The direct flow measurement techniques used by building managers and engineers to characterize ventilation rates in mechanically ventilated buildings cannot be applied to naturally ventilated spaces. Other approaches for characterizing ventilation may require technical expertise for execution or data interpretation, or specialized instrumentation, which reduces accessibility. As educators, administrators, and building managers plan for safe operations in the wake of COVID-19, there is a need for practical approaches for characterizing ventilation on the room level, as well as support for small-scale, short-term decision making, e.g., with respect to opening windows and doors and running fans, air conditioners, or supplemental air cleaning.

Here, we describe efforts taken by this group of scientists and educators using different approaches to characterize ventilation in educational spaces in different U.S. locations in collaboration with facilities managers, administrators, and other decision makers. We discuss our findings, best practices, and lessons learned.

\section{Methodology}

In this section, we describe practical approaches for characterizing ventilation on a room level in universities and schools, highlighting their advantages and disadvantages. The approaches discussed are summarized in Table 1. Broadly, these can be classified as direct flow measurements, controlled-release studies, and passive in situ monitoring. Note that ventilation rates, especially in naturally ventilated spaces, are highly dependent on factors including but not limited to environmental conditions (indoor-outdoor temperature difference, wind speed, etc.) and occupancy.

We have used the approaches summarized in Table 1, alone and in combination, to characterize ventilation on a room level in classrooms and other educational spaces. They require instrumentation of varying levels of sophistication, ranging from low-cost (anemometer/velocity probe, nondispersive infrared (NDIR) $\mathrm{CO}_{2}$ sensors, low cost $\mathrm{PM}_{2.5}$ sensors) to research-grade. Some instrumentation may serve multiple purposes, for example, NDIR $\mathrm{CO}_{2}$ sensors can be used for controlled-release experiments as well as passive monitoring. Operation of the instruments and execution of the measurements requires varying levels of training. The use of lower-cost sensors allows measurement in several rooms simultaneously, or use of several monitors in a single room to assess spatial variability in tracer concentrations (mixing). Passive monitoring with user-friendly sensors will be more accessible to nonspecialists than other techniques such as balometry and controlled release experiments, and may be used as part of a long-term strategy for indoor air quality management.

The ventilation metrics discussed here are summarized in Table 2. Ventilation rate is generally expressed as air volume per unit time (and sometimes per occupant). Mitigating the spread of airborne disease requires different metrics. Since the goal is to minimize the steady-state

concentration of pathogens exhaled by an infected individual within a room's air, relevant metrics capture how frequently the room's air is flushed, regardless of the number of occupants.

2.1 Direct flow measurements. Direct measurements of air flow in ducts are the most basic and commonly accepted method (ASHRAE 2017) for measuring ventilation on a room scale. As a first pass, or when resources are low, a simple check using tissue paper may be used to determine if air flow exists and identify malfunctioning air handling equipment. In more sophisticated measurements, a balometer (essentially a portable hood that measures volumetric flow rate from supply grilles) or velocity probe is used to measure flow into and out of the room through supply and return grilles. For more information, see ASHRAE (2017). Air changes per hour $\left(\mathrm{ACH}, \mathrm{h}^{-1}\right)$, or the rate at which room air is replaced, can be calculated from balometer measurements by dividing the incoming volumetric air flow rate by the room volume. This is also commonly referred to as the air exchange rate. ACH calculated using direct flow measurement data will include both recirculated and outdoor air. An obvious major disadvantage of the direct-flow approach is that it cannot be used for spaces without mechanical ventilation, nor can it be used to test the impact of opening doors and windows. For naturally ventilated spaces, another approach is needed. 
Table 1

Summary of approaches for characterizing ventilation on a room level.

\begin{tabular}{|c|c|c|c|}
\hline Approach & Technique & Advantages & Disadvantages \\
\hline Direct Flow & $\begin{array}{l}\text { Balometer or } \\
\text { anemometer }\end{array}$ & $\begin{array}{l}\text { - Accepted } \\
\text { method, accessible to } \\
\text { building managers } \\
\text { - Measures total flow of } \\
\text { recirculated + outdoor } \\
\text { air }\end{array}$ & $\begin{array}{l}\text { - Inconclusive } \\
\text { measurements in } \\
\text { spaces with no } \\
\text { mechanical } \\
\text { ventilation } \\
\text { - Not possible to } \\
\text { separate outdoor and } \\
\text { recirculated air } \\
\text { exchange rates with } \\
\text { this measurement } \\
\text { alone }\end{array}$ \\
\hline \multirow[t]{3}{*}{$\begin{array}{l}\text { Controlled } \\
\text { Release }\end{array}$} & $\mathrm{CH}_{4}$ or $\mathrm{C}_{2} \mathrm{H}_{6}$ & $\begin{array}{l}\text { - Indicates outdoor air } \\
\text { exchange rate, gives } \\
\text { results for spaces with } \\
\text { no mechanical } \\
\text { ventilation } \\
\text { - Low natural } \\
\text { background } \\
\text { - High sensitivity } \\
\text { - Few indoor sources, } \\
\text { occupancy does not } \\
\text { interfere with } \\
\text { measurements }\end{array}$ & $\begin{array}{l}\text { - Generally requires } \\
\text { research } \\
\text { instrumentation } \\
\text { - Flammable gas }\end{array}$ \\
\hline & $\mathrm{CO}_{2}$ & $\begin{array}{l}\text { - Gives results for spaces } \\
\text { with no mechanical } \\
\text { ventilation } \\
\text { - Low-cost, reliable } \\
\text { sensors readily available } \\
\text { - Non-flammable, } \\
\text { readily available gas }\end{array}$ & $\begin{array}{l}\text { - Requires empty } \\
\text { room since } \mathrm{CO}_{2} \\
\text { emission from the } \\
\text { occupants interfere } \\
\text { with measurements } \\
\text { - Potential for } \\
\text { interference from } \\
\text { recirculated } \mathrm{CO}_{2}\end{array}$ \\
\hline & $\begin{array}{l}\text { noninfectious } \\
\text { aerosol } \\
\text { particles }\end{array}$ & $\begin{array}{l}\text { - Dispersion } \\
\text { experiments provide } \\
\text { insight into airflow } \\
\text { patterns, movement of } \\
\text { aerosol within a space }\end{array}$ & $\begin{array}{l}\text { - Technically } \\
\text { challenging to } \\
\text { generate and detect } \\
\text { aerosols } \\
\text { - Loss of particles to } \\
\text { surfaces, filtration, } \\
\text { and resuspension } \\
\text { must be accounted } \\
\text { for }\end{array}$ \\
\hline \multirow[t]{2}{*}{ Passive } & $\mathrm{CO}_{2}$ & $\begin{array}{l}\text { - Collect data during } \\
\text { normal facility } \\
\text { operation, occupancy } \\
\text { - No expertise required } \\
\text { - Directly shows of the } \\
\text { impact of human } \\
\text { exhalation on indoor air }\end{array}$ & $\begin{array}{l}\text { - Uncontrolled } \\
\text { conditions } \\
\text { complicate } \\
\text { interpretation of the } \\
\text { results } \\
\text { - Other } \mathrm{CO}_{2} \text { sources } \\
\text { (vehicles, cooking, } \\
\text { recirculated air) may } \\
\text { cause interference }\end{array}$ \\
\hline & $\mathrm{PM}_{2}$ & $\begin{array}{l}\text { - Provides valuable } \\
\text { indoor air quality data } \\
\text { during normal facility } \\
\text { operation } \\
\text { - Characterize impact of } \\
\text { indoor air pollution } \\
\text { sources }\end{array}$ & $\begin{array}{l}\text { - Uncontrolled } \\
\text { conditions } \\
\text { complicate } \\
\text { interpretation of the } \\
\text { results } \\
\text { - Respiratory } \\
\text { particles are greatly } \\
\text { outnumbered by } \\
\text { 'background' PM } \\
\text { - Loss of particles to } \\
\text { surfaces, filtration, } \\
\text { and resuspension } \\
\text { must be accounted } \\
\text { for }\end{array}$ \\
\hline
\end{tabular}

2.2 Controlled release. Another family of approaches for characterizing ventilation in indoor spaces involves releasing a fixed quantity of an inert tracer substance and observing its decay with time (Charlesworth 1988; Persily 1988, 2016). A major advantage of controlled-release measurements is that this approach provides ventilation data for naturally ventilated spaces as well as mechanically ventilated ones. These experiments provide an ability to quantitatively
Table 2

Ventilation parameters and their definitions.

\begin{tabular}{|c|c|c|}
\hline Parameter & Units & Definition \\
\hline Ventilation rate & $\begin{array}{l}\mathrm{L} \mathrm{s}^{-1} \text { or } \mathrm{L} \mathrm{s} \mathrm{s}^{-1} \\
\text { person }^{-1}\end{array}$ & $\begin{array}{l}\text { Volumetric rate of delivery or Volumetric } \\
\text { rate of air delivery, per occupant }\end{array}$ \\
\hline $\begin{array}{l}\text { Air changes per hour } \\
\text { (ACH) }\end{array}$ & $\mathrm{h}^{-1}$ & $\begin{array}{l}\text { Rate at which room air is replaced by } \\
\text { recirculated and outdoor air and equals } \\
\text { volumetric ventilation rate normalized to } \\
\text { room volume }\end{array}$ \\
\hline $\begin{array}{r}\text { Tracer air changes } \\
\text { per hour }\left(\mathrm{ACH}_{\mathrm{T}}\right)\end{array}$ & $h^{-1}$ & $\begin{array}{l}\text { ACH as determined by measuring the } \\
\text { decay of a tracer species }\end{array}$ \\
\hline $\begin{array}{l}\text { Balometer air } \\
\text { changes per hour } \\
\left(\mathrm{ACH}_{\mathrm{B}}\right)\end{array}$ & $\mathrm{h}^{-1}$ & $\begin{array}{l}\mathrm{ACH} \text { as determined via balometry } \\
\text { measurements }\end{array}$ \\
\hline$\tau$ & $\mathrm{h}$ & Air change timescale \\
\hline
\end{tabular}

test ventilation scenarios to support policy decisions. Controlled-release experiments measure the total ventilation, which could include some infiltration or exfiltration as well as airflow through design openings (windows). Tracer substances employed may include gases such as $\mathrm{CO}_{2}$, $\mathrm{CH}_{4}, \mathrm{C}_{2} \mathrm{H}_{6}$, volatile organic compounds (VOCs), $\mathrm{SF}_{6}$, or particulate matter (PM). Note that, for some gas tracers, particularly VOCs, reactive or deposition loss is possible. In PM tracer studies, particle deposition or filtration must be accounted for. Resuspension of deposited particles is also possible and should be considered in the data analysis. If humans or their activities emit the tracer substance (e.g., in the case of $\mathrm{CO}_{2}$ or $\mathrm{PM}$ ) indoors, or if the tracer may be considered harmful to health at the levels used for the test, the room must be unoccupied during the measurement. Occupancy and furnishings may also affect air flow, e.g. by enhancing mixing or obstructing air flow. Fans should be used to disperse the tracer species throughout the space, and mixing should be verified with measurements in different locations throughout the space. Under the assumption of well-mixed conditions and no sources of emission, the mass balance for a substance in a given space is described as follows:

$\frac{d C}{d t}=-\frac{1}{\tau}\left(C-C_{\text {background }}\right)$

where $C$ is the concentration of the tracer substance in the room, $t$ is time, $\tau$ is the air change timescale, and $C_{\text {background }}$ is the background concentration of the tracer substance in the room when ventilation is operated at a specified condition but no tracer substance has been released. By introducing a corrected concentration variable, $\widehat{C}=C-$ $C_{\text {background }}$, Eq. (1) simplifies into:

$\frac{d \widehat{C}}{d t}=-\frac{1}{\tau} \widehat{C}$

Thus, $\tau$ can be determined as the inverse slope of the linear regression line of natural logarithm of $\widehat{C}$ versus time. Note that if sources of the tracer compound are present, $C_{\text {background }}$ may vary with time, resulting in nonlinearity of this relationship. Once exponential decay is confirmed, analysis can be simplified by calculating $\tau$ as the $e$-folding time, or the time for the peak concentration to be reduced by a factor of $e$. We define $\mathrm{ACH}_{\mathrm{T}}$ (ACH as inferred from tracer decay observations) as follows:

$\mathrm{ACH}_{\mathrm{T}}=\frac{1}{\tau}$

Fig. 1 shows typical data from a controlled-release $\mathrm{CO}_{2}$ experiment exhibiting exponential decay, consistent with equation (2).

$\mathrm{ACH}_{\mathrm{T}}$ may differ from ACH determined via flow measurements. In naturally ventilated or mechanically ventilated spaces with no recirculation or other air exchange between rooms, $C_{\text {background }}$ is the outdoor concentration of the tracer and $\mathrm{ACH}_{\mathrm{T}}$ can be interpreted as the rate at which room air is replaced with outdoor air. This is also true for mechanically ventilated spaces with recirculation as long as there are no sources of the tracer elsewhere in the building. The potential exists for interference in $\mathrm{CO}_{2}$ decay measurements in a densely occupied building 

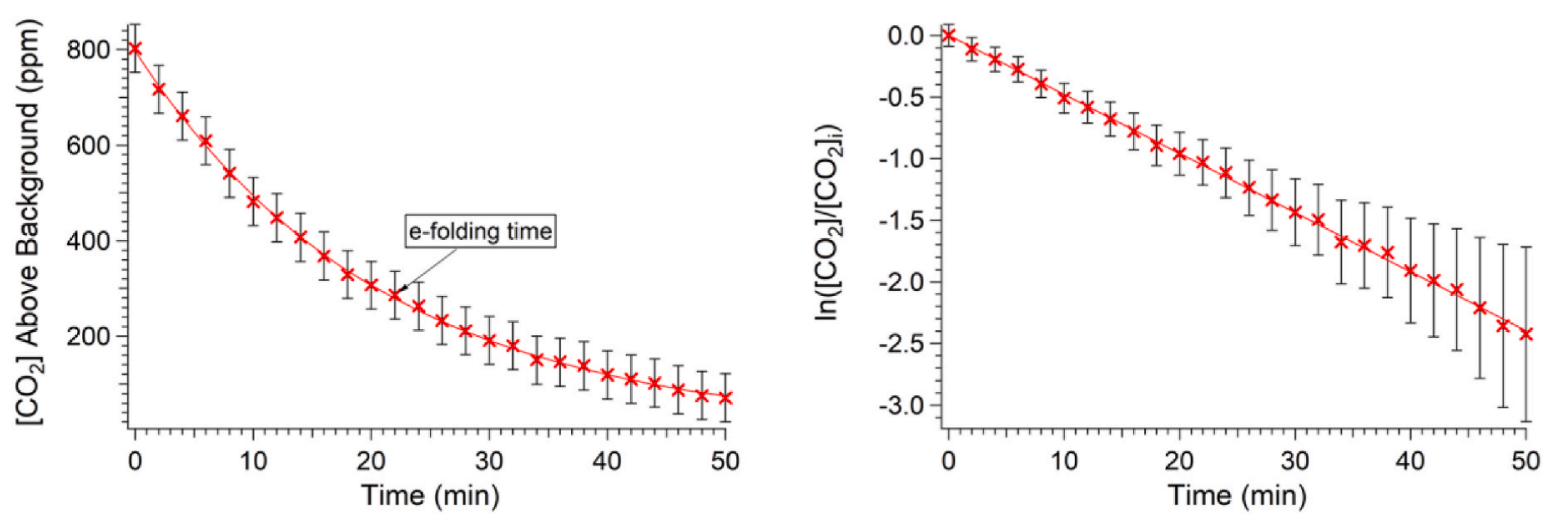

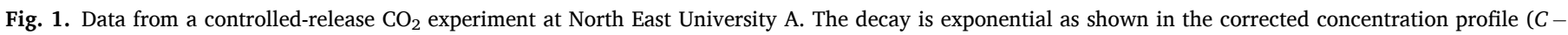
$C_{\text {background }}$ ) on the left. $\mathrm{ACH}_{\mathrm{T}}$ is calculated either from the e-folding time or via a linear fit to the log-linear plot. See the Results section for more details.

with air recirculation or other sources of mixing between rooms. $\mathrm{CO}_{2}$ transported from occupied rooms would result in an elevated $\mathrm{CO}_{2}$ baseline reading and potentially interfere with measured decay rates. (Note that, at the time of writing, the background outdoor $\mathrm{CO}_{2}$ concentration in North America is $\sim 415$ ppm (NOAA, 2021)). Similarly, small natural gas leaks can cause interference when $\mathrm{CH}_{4}$ or $\mathrm{C}_{2} \mathrm{H}_{6}$ is used as the tracer and a sensitive detector is used. Simultaneous measurement of the tracer in the recirculated air is recommended in those cases. $\mathrm{ACH}_{\mathrm{T}}$ measurements can be complemented with direct flow measurements for a more complete picture. For PM decay studies in such a scenario, if HVAC filtration effectively removes $\mathrm{PM}$ from recirculated air, $\mathrm{ACH}_{\mathrm{T}}$ is the sum of the outdoor and filtered air change rates, and $C_{\text {background }}$ would be lower than the outdoor PM concentration.

The choice of tracer substance depends on a number of factors, including the availability of the substance and a suitable detector for the measurement, and the technical complexity of the measurement. Despite the potential for interference described above, $\mathrm{CO}_{2}$ gas is a widely used tracer for controlled-release experiments. The gas itself is non-flammable and non-toxic at low levels. It is available in gas cylinders from specialty gas or food service suppliers, or in the form of dry ice or canisters for limited studies or demonstrations. Low-cost ( USD $\$ 100-200)$ NDIR $\mathrm{CO}_{2}$ sensors are readily available and can be repurposed for in situ monitoring after the experiment. $\mathrm{CH}_{4}$ and $\mathrm{C}_{2} \mathrm{H}_{6}$ studies have several advantages over $\mathrm{CO}_{2}$ in that (i) these gases are not emitted by humans so the presence of occupants in the room or elsewhere in the building does not interfere with the test (ii) these gases have a comparatively low natural background concentration (1 ppm for $\mathrm{CH}_{4}$ ), allowing high sensitivity in large rooms. However, one disadvantage is that higher-cost ( $\sim$ USD $\$ 48,000)$ research-grade instrumentation is required for sensitive, low noise, high-frequency measurements of $\mathrm{CH}_{4}$ and $\mathrm{C}_{2} \mathrm{H}_{6}$. Lower-cost and lower-sensitivity NDIR methane sensors do exist and could potentially be a more affordable alternative, but we have not tested them. $\mathrm{SF}_{6}$ has similar advantages to $\mathrm{CH}_{4}$ and $\mathrm{C}_{2} \mathrm{H}_{6}$, but it has fallen out of use in recent years as it has become recognized as a potent greenhouse gas. $\mathrm{N}_{2} \mathrm{O}$ and several halocarbon gases have also been previously used (Persily 1988, 2016).

Controlled-release experiments using dispersion of non-infectious particles may provide insight into airflow patterns and movement of aerosol within a space. This information is especially relevant in the context of COVID-19-related ventilation concerns. Many tracer particle types are possible, including soot from a combustion source, organic aerosols, e.g. from a fog machine, inorganic salt aerosols such as $\mathrm{NaCl}$, or engineered particles with special properties such as fluorescence (Tang et al., 2020). The technical challenges of generating and detecting well-characterized aerosols make this more of a research exercise. There may also be challenges in securing permission for measurements and communicating the data, due to misunderstandings about infectious vs. noninfectious aerosols and safety concerns about inhalation.
Information can be inferred about particle dynamics in the space if different PM sizes are measured. We found that building activities which result in periodic aerosol release (i.e., disinfectant fogging) present an opportunity for a 'natural experiment' if appropriate detectors are in place. Low-cost PM sensors may be appropriate for these measurements although there is some concern about the data quality for many of the instruments on the market (Singer and Delp 2018) and attention must be paid to their calibration.

In addition to the considerations listed above, when analyzing the decay of tracer particles, one must account for the particle dynamics that remove PM from air that are not related to ventilation, such as surface deposition, as well as, possibly, resuspension. Therefore, tracer particle decay rates represent total aerosol removal from the room rather than purely room ventilation or ACH. Further research needs to be done investigating size dependence of aerosol decay as well as how aerosol decay directly compares to decay of other tracer gases and room ACH. However, the decay rates found by analyzing in situ $\mathrm{PM}_{2.5}$ levels, analogous to the total time that aerosols are suspended in the air, may more directly represent the potential time of exposure to particle contaminants under $2.5 \mu \mathrm{m}$ (including resuspended SARS-CoV-2-containing aerosols) than would a tracer gas-calculated ACH.

2.3 In situ monitoring. A third approach for characterizing ventilation in indoor spaces is the placement of sensors for one or more trace species in a space, for passive monitoring during normal facility operation (Rudnick and Milton, 2003; Batterman 2017; Peng and Jimenez, 2021). Tracers which are emitted by humans (e.g. $\mathrm{CO}_{2}$, aerosol, volatile organic compounds) and therefore will fluctuate with occupancy are especially appropriate. This approach is attractive in that it requires relatively little technical expertise and does not disrupt operations. Collecting data during normal occupancy provides a direct measure of the impact of human exhalation on indoor air. Passive $\mathrm{CO}_{2}$ data can also be useful as a real-time proxy of occupancy that shows daily usage schedules, and may reveal unexpected trends in room usage. In the best case, the real-time data can be linked into publicly visible outputs to support decision making. Long-term in situ monitoring of $\mathrm{CO}_{2}$ can be accomplished with the same low-cost sensors used for controlled-release experiments, reducing capital investment.

In situ monitoring during events such as in-person classes, which can lead to a buildup of $\mathrm{CO}_{2}$, and fogging events which occur when a room is disinfected with a cleaning aerosol spray, allow for calculation of the room $\mathrm{ACH}_{\mathrm{T}}$. This approach is demonstrated in Fig. 2 using data from the two classrooms at the South East University. $\mathrm{CO}_{2}$ decay after an inperson class is shown in panel A. Note that occupancy in the building was low during the period of these measurements so no interference from $\mathrm{CO}_{2}$ in other rooms is observed. $\mathrm{ACH}_{\mathrm{T}}$ was estimated using Equations (1) and (2), analyzing the in situ buildup in $\mathrm{CO}_{2}$ levels during room occupancy and the resulting exponential $\mathrm{CO}_{2}$ decay after the occupants left the room. $\mathrm{PM}_{2.5}$ data for a fogging episode in another classroom is 

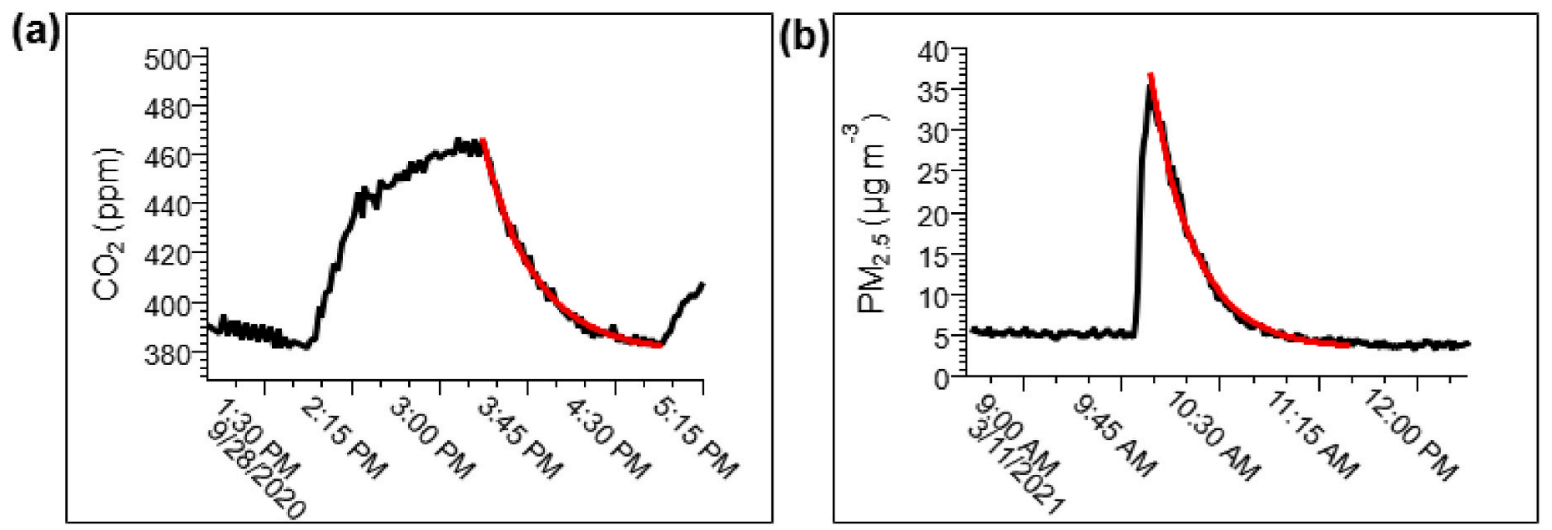

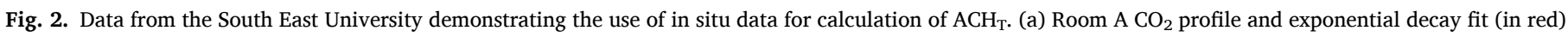

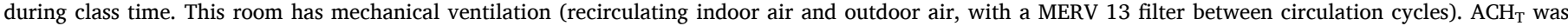

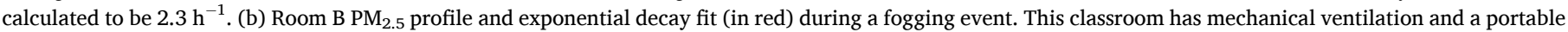

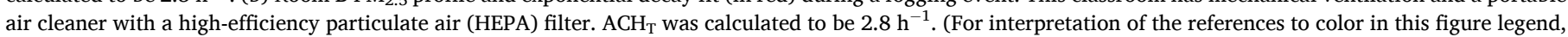
the reader is referred to the Web version of this article.)

shown in panel B. $\mathrm{PM}_{2.5}$ levels in the room varied no more than 1-5 $\mu \mathrm{g}$ / $\mathrm{m} 3$ during class time, indicating that the concentration of aerosols produced by fogging (an order of magnitude higher) should not be greatly affected by potential particle resuspension or accumulation during the monitored decay. $\mathrm{ACH}_{\mathrm{T}}$ was calculated from in situ PM data following the same exponential decay model. For additional details see the Results section.

The main limitation of the in situ approach is that uncontrolled conditions complicate interpretation of the results. Direct quantification of ventilation parameters is difficult with this method. Usually, the tendency of the tracer levels to stay within a range (e.g., 600-800 ppm $\mathrm{CO}_{2}$ ) is taken as an indicator of sufficient or insufficient ventilation. Sometimes, transient events, such as a gathering of people in a space, may cause temporary buildup of the tracer, allowing observation of its decay and calculation of the air change timescale as described in the previous section. Interference may be caused by other sources of $\mathrm{CO}_{2}$, such as cooking or vehicles in a garage or near an air intake. As in controlled release $\mathrm{CO}_{2}$ experiments, interference from $\mathrm{CO}_{2}$ recirculated or otherwise mixed

from other spaces in the building may also be an issue. For this reason, ideally, $\mathrm{CO}_{2}$ should be measured in the supply air as well as room air.

In situ monitoring of aerosols may lead to confusion in the COVID-19 context since respiratory particles are greatly outnumbered by 'background' PM indoors, as well other particles generated by human activities such as resuspended floor dust, skin flakes and clothing fibers. Therefore, number-based monitoring would not allow detection of a respiratory aerosol signature. Detection of virus-containing respiratory particles requires advanced sampling methods and instrumentation (Lednicky et al., 2020). Selective monitoring of a subset of the indoor aerosol (e.g., Bhangar et al., 2014), or analysis of the particle size distribution data may reveal subtle trends linked to human emissions, but will require further research.

\section{Results}

Here we describe ventilation studies conducted by this group using the methods described in the previous section. Controlled-release methods were used in a university and a secondary school in Southern California, two universities in the Northeast with facilities with a range of ages, and two K-12 school districts in Coastal California. Passive sampling was used in a university in the Southeast U.S. and one in the Mountain West. These institutions are referred to herein using pseudonyms.

3.1 North East University A. Controlled-release $\mathrm{CO}_{2}$ experiments were performed between August-December 2020 in nine buildings across two of the University's campuses, located in a dense urban area within a three mile radius. Relatively newer buildings with mechanical ventilation (built 1961-1996) and older buildings (built 1897-1911) were studied. The older buildings were originally constructed with steam heat and natural ventilation but were later fully or partially retrofitted with mechanical ventilation. In buildings with partial mechanical ventilation, certain parts of the building relied only on natural ventilation. Classrooms to be studied were initially prioritized based on an informal survey of faculty and student recollections of thermal comfort and perceived air quality. Once the method was established and trust was developed with campus facilities and administration, the scope of the measurements was expanded to include a broad survey of classrooms, conference rooms, and elevators.

The spaces were unoccupied during and immediately before each test. A baseline $\mathrm{CO}_{2}$ reading was taken before initiation of each experiment. Experiments were performed by releasing compressed $\mathrm{CO}_{2}$ (TechAir) into each room with fans for mixing until a level of 1000-1500 ppm was reached as measured using calibrated NDIR $\mathrm{CO}_{2}$ sensors (Aranet4, Aranet) which were connected via Bluetooth to an Apple iPhone XR running Aranet software. The primary sensor was located close to the center of the space, while three auxiliary sensors were placed near the corners. Once the $\mathrm{CO}_{2}$ reading reached the target level and the room air was well-mixed (i.e. auxiliary sensor readings within $250 \mathrm{ppm}$ of primary sensor reading), the operator then exited the room and observed the decay of $\mathrm{CO}_{2}$ to the baseline via the Aranet software. $\mathrm{CO}_{2}$ levels in each case exhibited exponential decay consistent with equation (2) (cf. Fig. 1, Methodology section).

The differences between the measured baseline level ( $\left.C_{\text {background }}\right)$ and the outdoor background readings preceding the experiments were within the sensitivity of the sensor $(<50 \mathrm{ppm})$ for all but one classroom. This is consistent with the fact that the measurements were performed at a time of very low occupancy in the buildings. For the one exception observed, $C_{\text {background }}$ was $83 \mathrm{ppm}$ higher than the outdoor $\mathrm{CO}_{2}$ concentration. In this specific case, the experiment was conducted immediately following a controlled-release experiment in the adjacent classroom.

Results for classrooms are summarized in Fig. 3. In the newer and retrofitted buildings, ventilation was generally satisfactory, with 2.7 $\mathrm{h}^{-1} \leq \mathrm{ACH}_{\mathrm{T}} \leq 8.7 \mathrm{~h}^{-1}$ for classrooms. Some problem areas with $\mathrm{ACH}_{\mathrm{T}}$ substantially lower than $3 \mathrm{~h}^{-1}$ were identified in classrooms with natural ventilation in older buildings. The data were shared with campus facilities and administration, resulting in the installation of portable HEPA filter units in classrooms with $\mathrm{ACH}_{\mathrm{T}}<3 \mathrm{~h}^{-1}$ across campus.

In parallel with the tracer measurement effort, an independent 


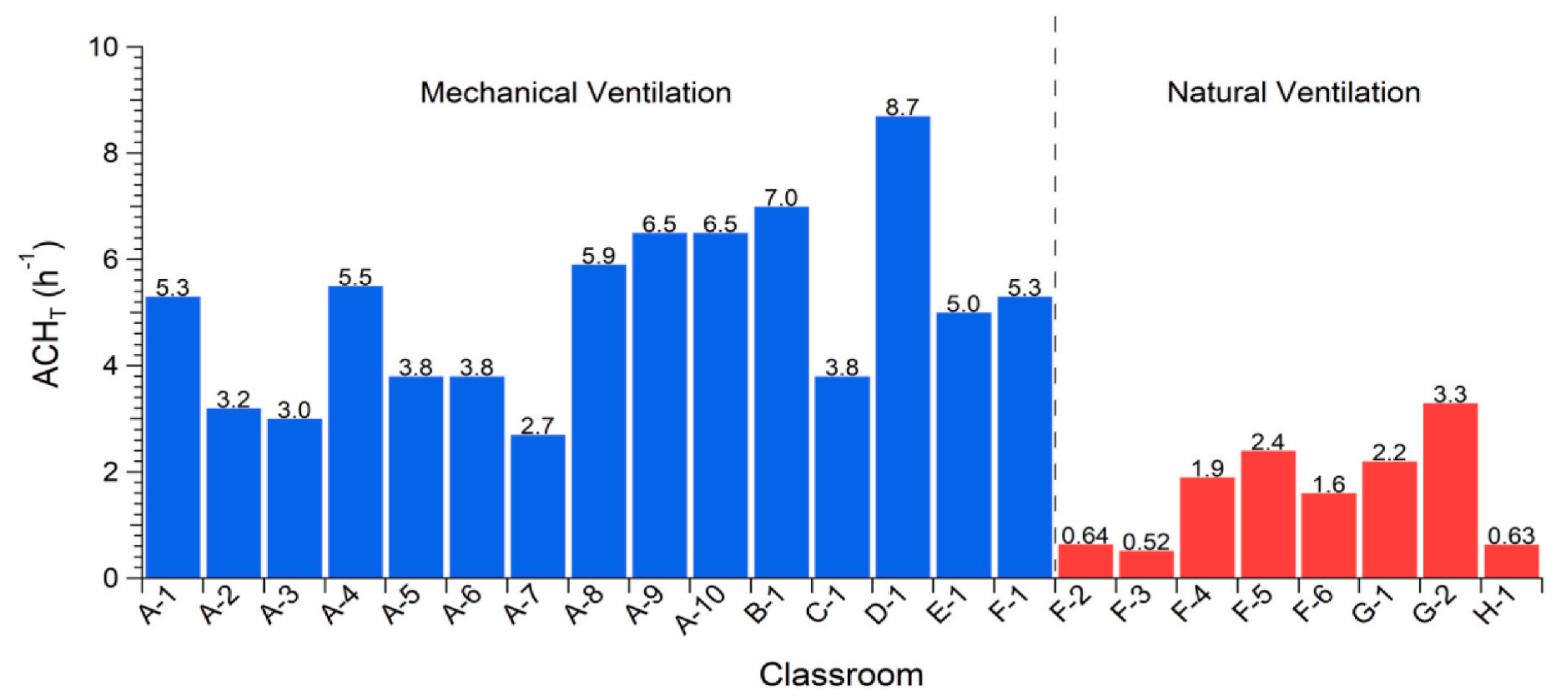

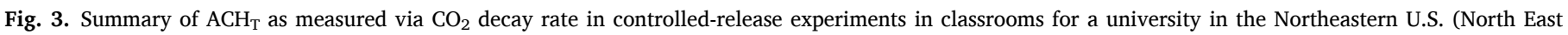
University A) with a mix of mechanical and natural ventilation.

engineering firm conducted balometer measurements at the supply inlets of some of the mechanically ventilated classrooms that we characterized. Measurements were not made on the same days, so differences in weather conditions (indoor-outdoor temperature difference, wind speed, heating/cooling load, etc.) and HVAC operation on those days may be a source of discrepancy (Batterman 2017). Comparison between results of the controlled-release measurements and balometer measurements is shown in Fig. 4. The buildings had been set for maximum air intake before these measurements were made, and there was relatively low occupancy due to remote study and COVID-19 related occupancy restrictions at the time of the measurements. Ventilation was satisfactory for all of the rooms in this measurement set, by both measures $\left(\mathrm{ACH}_{\mathrm{T}}\right.$ and $\left.\mathrm{ACH}_{\mathrm{B}} \geq 3 \mathrm{~h}^{-1}\right)$. The two sets of measurements exhibited general agreement for most of the compared classrooms. However.

there were significant disparities, up to $6.2 \mathrm{~h}^{-1}$ among the remaining $25 \%$ of the classrooms, where the balometer results were substantially greater than the controlled-release results. The low baseline $\mathrm{CO}_{2}$ concentrations that we observed, consistent with the low building occupancy, allowed us to rule out recirculated $\mathrm{CO}_{2}$ as a major contributor to the observed differences. Some discrepancies may be attributable to the fact that the balometer measurements and controlled-release studies in each classroom were made 2-4 weeks apart during the summer-autumn transition, so cooling and heating conditions varied. HVAC settings were also changed during this time period. In one case, a relatively high $\mathrm{ACH}_{\mathrm{B}}$ as compared to $\mathrm{ACH}_{\mathrm{T}}$ alerted the facilities manager that outdoor air intake to the building had not yet been increased, and adjustments were made. Besides the classroom measurements, tracer measurements were also conducted in ten conference rooms and four elevators in four different mechanically ventilated buildings. Two out of the ten conference rooms had inadequate ventilation $\left(\mathrm{ACH}_{\mathrm{T}}<3 \mathrm{~h}^{-1}\right)$ and were subsequently equipped with HEPA filter units by facilities. All of the four stationary elevators were well-ventilated $\left(\mathrm{ACH}_{\mathrm{T}}>5 \mathrm{~h}^{-1}\right)$, even reaching values as high as $21 \mathrm{~h}^{-1}$.

3.2 Coastal California K-12 Schools Controlled release of $\mathrm{CO}_{2}$ experiments using the same methodology as described above for North East University A were performed in 50 classrooms across two K-12 school districts in Coastal California, which included preschool, elementary, junior high and senior high schools. These neighboring districts are in a temperate zone where the majority of classrooms were designed with natural ventilation. Many of these classrooms therefore had large windows and most had exterior hallways so classroom doors open directly to the outside, enabling cross-flow. Researchers trained facilities personnel to conduct $\mathrm{CO}_{2}$ decay measurements using Aranet4 NDIR $\mathrm{CO}_{2}$ sensors. Facilities personnel then performed experiments and sent $\mathrm{CO}_{2}$ data to the researchers for analysis. Measurements were performed during January-March 2021. Within each school, the architecture consisted of many similar classroom arrangements and

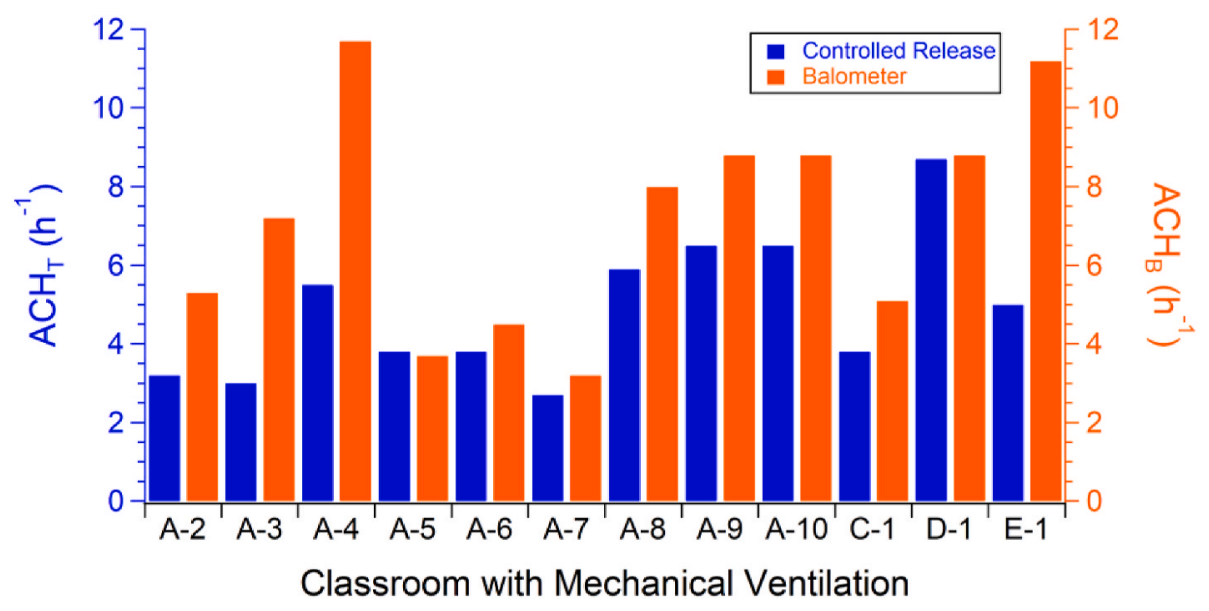

Fig. 4. Comparison between the controlled release $\mathrm{CO}_{2}$ decay rate and balometer air change measurements for North East university A. 
architectures. Therefore, in each school, only a selection of representative classrooms were measured. In each of those classrooms, $\mathrm{CO}_{2}$ monitors were placed at three separate locations with respect to the windows and doors. $\mathrm{ACH}_{\mathrm{T}}$ was measured first in the "sealed" room with doors and windows closed and HVAC turned off (if available). Once $\mathrm{CO}_{2}$ returned to background levels, the controlled-release experiment was then repeated under a variety of other conditions: 1) windows open, 2) windows and doors open (usually on different walls leading to cross flow), 3) with the ventilation system on (when available), and 4) with a fan facing out of a doorway or open window. Experiment (4) was only performed in rooms that were suspected by facilities personnel to have ventilation issues. The results are summarized in Fig. 5. Measurements were taken only on relatively calm days without unusually high wind speed, though a few schools located on coastal bluffs are generally breezy. This led to a dataset of approximately 460 measurements across 50 classrooms.

As observed in North East University A, $\mathrm{CO}_{2}$ levels showed simple exponential decay in the majority of rooms and conditions, and were accurately fit as described in the Methodology section. Representative curves are shown in Fig. 6. As seen in Fig. 5, none of the classrooms studied had $\mathrm{ACH}_{\mathrm{T}}>3 \mathrm{~h}^{-1}$ with closed windows and doors. Unsurprisingly, opening one or two exterior doors increased the overall ventilation rate dramatically; opening windows in addition to exterior doors led to $\mathrm{ACH}>5 \mathrm{~h}^{-1}$ in $>90 \%$ of classrooms measured. Panels (c) and (d) on Fig. 6 highlight the additional insight and information that was made possible by using multiple sensors to simultaneously measure $\mathrm{CO}_{2}$ levels in different locations within each room. In most cases (panels a-b), there is no difference in $\mathrm{ACH}_{\mathrm{T}}$ measured at different locations within the room. However, some other rooms showed a positional lag, where $\mathrm{CO}_{2}$ levels in some locations stayed constant for several minutes after the room was opened, before beginning to decay. Fig. $6 \mathrm{c}$ shows.

data from a room that showed very little $\mathrm{CO}_{2}$ decay when the doors and windows were sealed. Once two doors were opened, the front, middle, and back of the room still showed no decay for the first 4, 8, and $11 \mathrm{~min}$. The onset of decay traveled from one open door towards the other over approximately $10 \mathrm{~min}$, more reminiscent of a plug flow than the continuously-stirred, well-mixed assumption that leads to eq (2). In this room and others, opening windows or adding mechanical ventilation typically reduced or eliminated this lag. Another example, shown in Fig. 6d, shows differences in air turnover rates measured within a classroom containing a small alcove set off from the main classroom area. $\mathrm{CO}_{2}$ decay within the alcove lagged sensors in the main classroom by a few minutes with the door and windows open. While the main room had a high air turnover frequency $\left(\sim 17 \mathrm{~h}^{-1}\right)$, the alcove was lower $(\sim 10$ $\mathrm{h}^{-1}$ ). Placing a fan at the door, directed outwards, eliminated the lag in the alcove. Curiously, the added fan actually lowered the general room ACH $\left(17 \mathrm{~h}^{-1}\right.$ to $13 \mathrm{~h}^{-1}$, alcove from $10 \mathrm{~h}^{-1}$ to $\left.9 \mathrm{~h}^{-1}\right)$, suggesting that the door served as a natural inlet for airflow, which the fan's orientation opposed. Despite these spatial heterogeneities, air turnover was well above target in all locations measured. In a less well-ventilated space, problem zones such as the alcove could be addressed via use of portable air cleaners.

3.3 Southern California University. Controlled release of methane $\left(\mathrm{CH}_{4}\right)$, combined with a portable, scientific-grade methane and ethane detector (Picarro GasScouter, a mid-IR cavity-ringdown spectrometer) was employed to measure fresh-air ventilation rates in 21 buildings across the campus from July 2020 through April 2021. Tested buildings were mostly large, monolithic, multistory buildings whose construction spans the past 100 years, and comprise a mixture of laboratory, classroom, meeting, and office spaces. All buildings are mechanically ventilated, and most of the buildings have operable windows. The high data quality (rapid sample rate, low noise) of this sensor allows shorter experiments as well as more confident interpretation of subtle features in decay curves. These advantages are balanced by the substantial cost of the instrumentation; in our case it was also being used for other research studies. Methane ( $1 \%$ in $\mathrm{N}_{2}$ to exclude the possibility of ignition) was

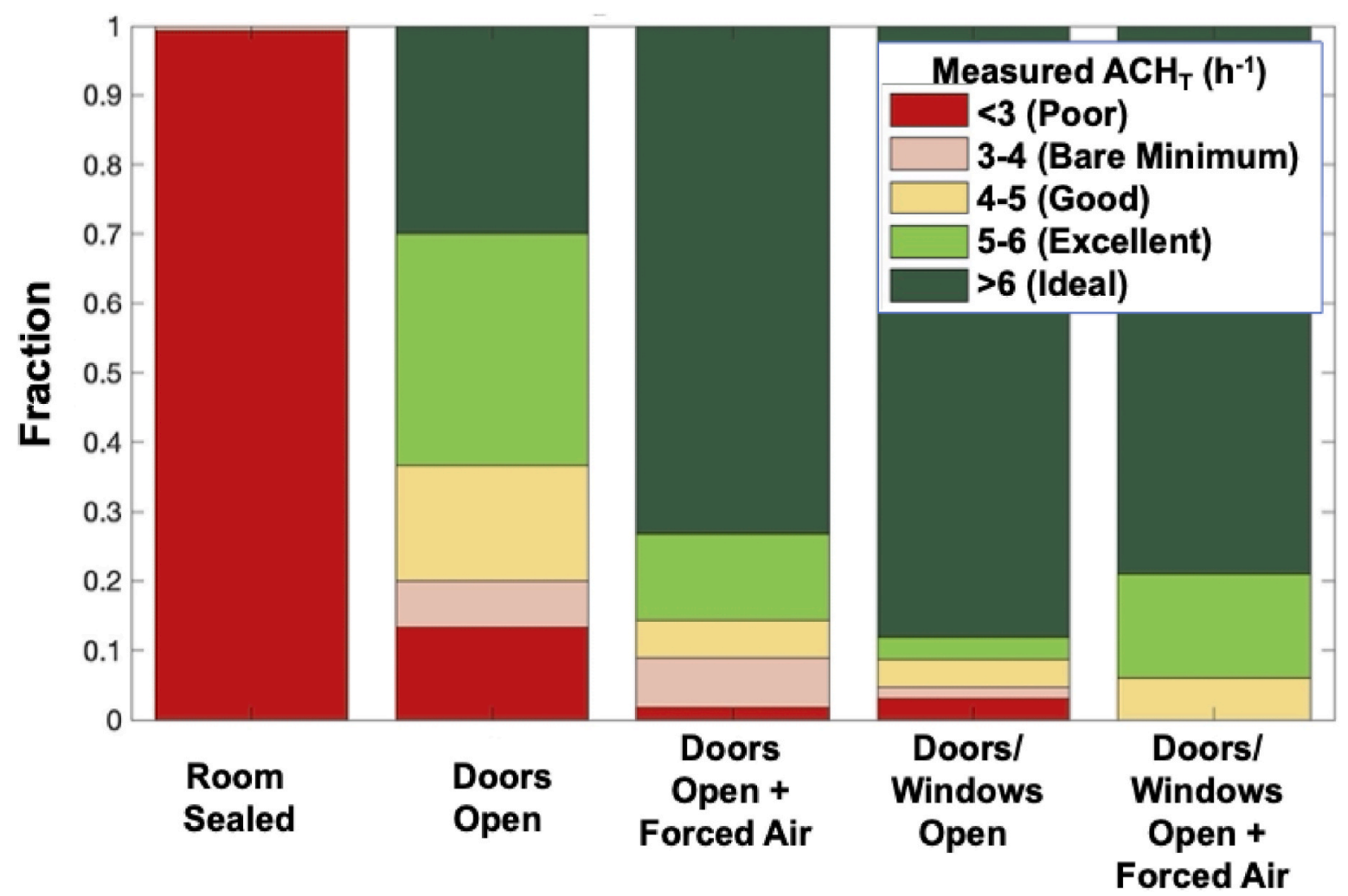

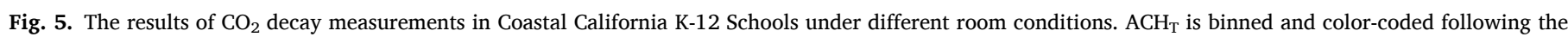

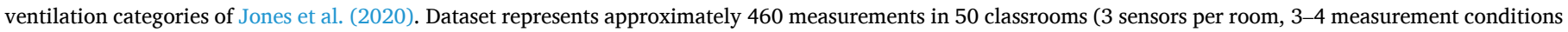
per room). (For interpretation of the references to color in this figure legend, the reader is referred to the Web version of this article.) 


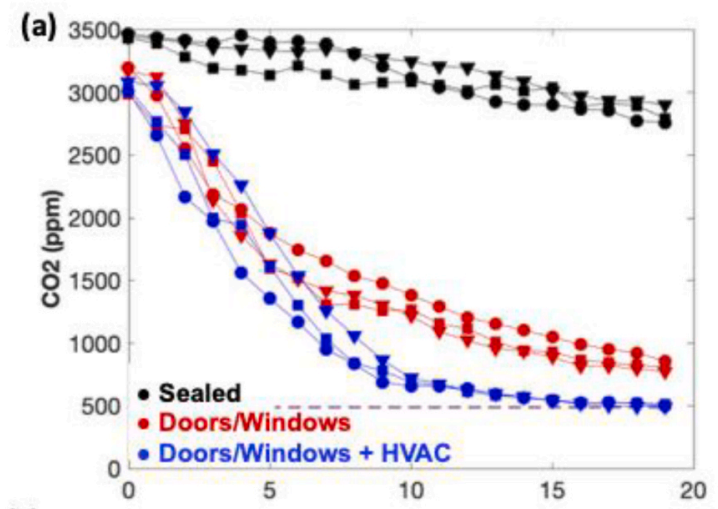

(c)

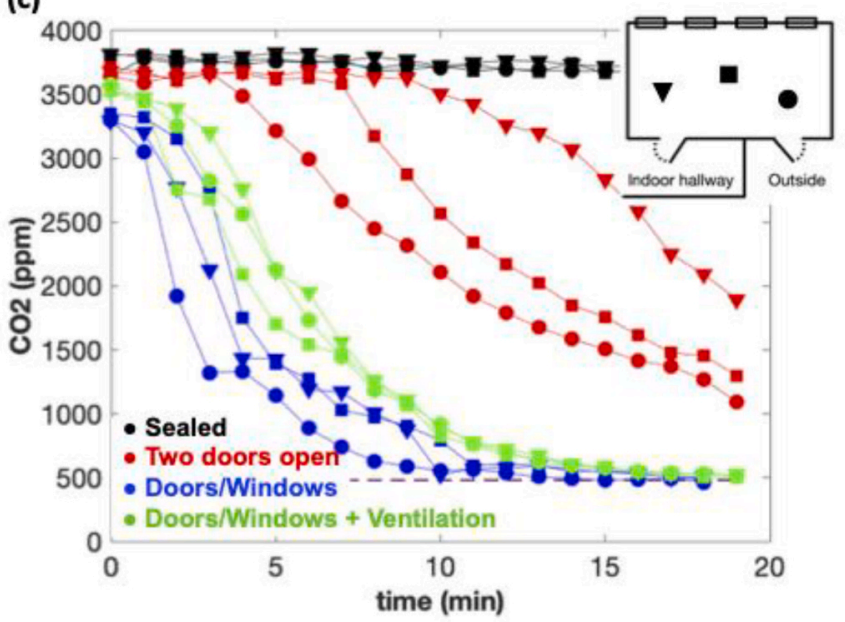

(b)

(d)
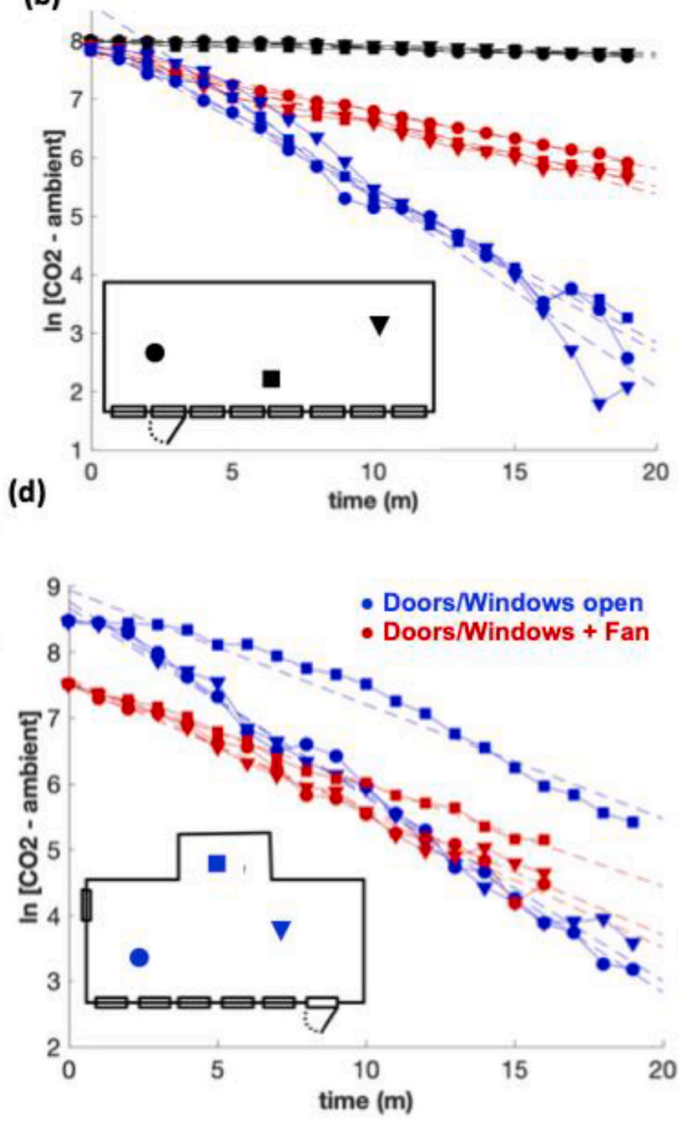

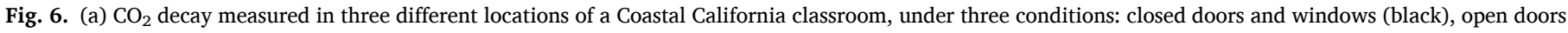

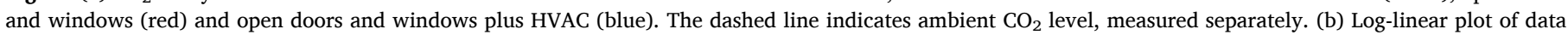

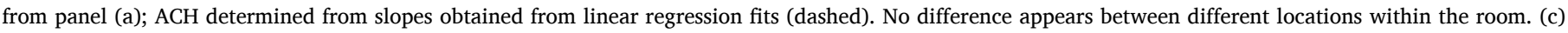

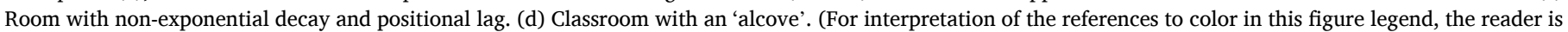
referred to the Web version of this article.)

added to a room using a $700 \mathrm{cfm}$ shop fan to boost the ambient concentration to $10-20 \mathrm{ppm}$, then decay was monitored to below $30 \%$ of peak concentration, typically for 10-40 min. Using this approach, one person is able to test $8-12$ rooms per day, with repeat measurements. We have measured rooms up to $1500 \mathrm{ft}^{2}$, with the primary limitation being the ability to keep room air well mixed.

Test results for two research labs are shown in Fig. 7, plotted as a function of elapsed time with a logarithmic concentration axis. When exponential tracer decay is plotted in this log-linear space, transient changes in ventilation rate can be visually identified as breaks in the slope. The results for Lab 1 are typical for a room with isolated HVAC supply and no recirculated air. Lab 2 exhibited an unexpectedly rapid drop in tracer at the beginning of the test, which we can interpret as resulting from dilution of the tracer into an adjacent space that shares ventilation with Lab 2. Occupants of the two rooms would not be effectively isolated from each other. This demonstrates the utility of high-performance measurements in finding unexpected (and perhaps undocumented) aberrations in HVAC system construction or operation.

After a period of initial method development and optimization, the methane test equipment has been deployed by the University's Facilities \& Operations staff, and is being used in support of reoccupation planning. Fig. 8 summarizes the data collected thus far. Fresh-air exchange rates varied from room to room, and building to building, over a very large range. Low values were typically encountered in offices and restrooms, and the highest values $\left(>10 \mathrm{~h}^{-1} \mathrm{ACH}_{\mathrm{T}}\right)$ almost all represent laboratory spaces. These ranges highlight the inherent difficulty of measuring a few spaces and extrapolating to others in the building. Note that many higher education laboratories are operated with $100 \%$ outside air ventilation. Also visible is a decline in the average airexchange rates from the oldest buildings through those built in the 1980 's, a result of historically increasing prioritization of energy efficiency, recirculation, and air-tight building construction.

3.4 Southern California Secondary School. The same methane tracer and Picarro GasScouter technique described in the previous section was also employed at a nearby secondary school during October 2020. The school comprises a campus of multiple buildings constructed over the past century, with a range of construction types from cottages and small (4-6 room) single-story buildings to larger, multistory monolithic buildings with $>30$ rooms. Given the moderate climate, similar to the California Coastal schools, many of the older buildings were originally built without forced-air heating or air conditioning, and were instead designed with large banks of windows on opposing walls to maximize natural ventilation. The tested rooms included classrooms, offices, and other specific-use spaces (dining, choir, theater) across a representative cross-section of buildings. Since leaving windows open all winter is a realistic option for this school, our initial interest was to compare ventilation rates with windows sealed and HVAC systems continually running, versus with windows open. Consistent with the Coastal California School study, comparison of 11 classrooms and offices demonstrated the clear benefit of opening windows, with ventilation in every space at least doubling, and increasing 3-fold or more in many rooms (Fig. 9). This led quickly to a decision that all windows would remain open when the school was occupied, regardless of outside temperature. In our experience, this ability to test scenarios and provide 


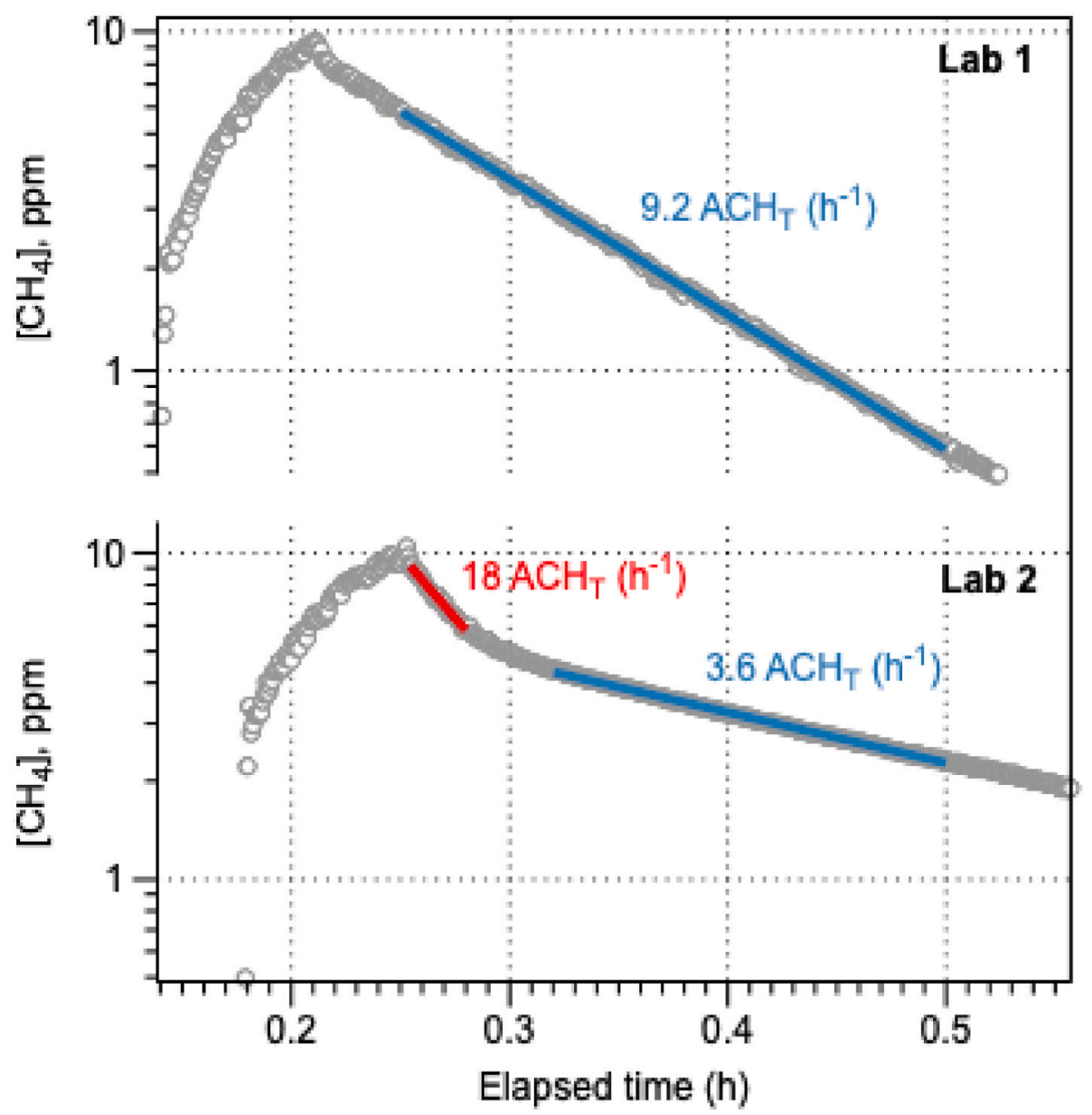

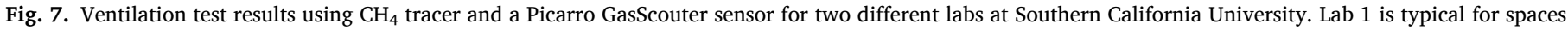

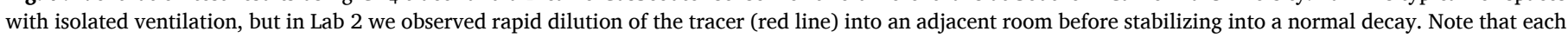
test lasted $<30 \mathrm{~min}$ total. (For interpretation of the references to color in this figure legend, the reader is referred to the Web version of this article.)

immediate, quantitative data to support policy decisions is one of the key benefits of the trace-gas testing methodology.

With the decision to keep windows open, all subsequent testing was done as such. Results are summarized in Fig. 10, which bins buildings by age of construction. This comparison emphasizes the contrast between older, smaller buildings with many windows, versus newer, larger buildings that rely on mechanical ventilation. Nevertheless, even the newest buildings all achieved $\geq 4 \mathrm{~h}^{-1} \mathrm{ACH}_{\mathrm{T}}$. In the older buildings, rooms with windows open achieved a stunning $21.3 \mathrm{~h}^{-1} \mathrm{ACH}_{\mathrm{T}}$ on average, levels that are more than 3 times the WHO guidelines even for healthcare settings $(6 \mathrm{ACH})$. These encouraging results provide a counterpoint to our findings in North East University A and B, that older buildings in cold climates, which were designed for heat retention, often have poor natural ventilation.

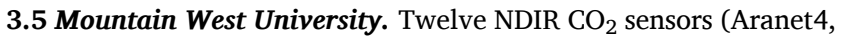
Aranet) were installed in mechanically ventilated rooms in buildings across the campus from September 2020 through April 2021 for passive in situ monitoring, with the goals of gaining insight into room usage and ventilation. Building construction dates spanned from 1985 (lecture classrooms) to 1999 (gym complex) and 2002 (music building). Information was shared with the campus facility managers to allow for optimization of ventilation. The rooms included four large ensemble music classrooms, two individual music practice rooms, two standard lecture classrooms, one science laboratory classroom, and three rooms in the campus gym facility. In all cases, ventilation is provided via forced air through centrally regulated HVAC units.

The sensors recorded $\mathrm{CO}_{2}$ levels every $2 \mathrm{~min}$. Data was averaged during typical main usage hours (08:00-22:00 for music classrooms and practice rooms; 09:00-15:00 for lecture classrooms; $15: 00-21: 00$ for the gym), over non-holiday weekday (Monday-Friday) periods during the academic term between September and April. Fig. 11a shows that during typical hours of operation, most rooms with sensors showed $\mathrm{CO}_{2}$ levels $<500 \mathrm{ppm}$ for $70-80 \%$ of measurements. The average of the three gym sensors showed higher average readings, though these measurements show that $95 \%$ of measurements were still $<800 \mathrm{ppm}$. These $\mathrm{CO}_{2}$ levels are within a range that would indicate satisfactory ventilation during full occupancy of the space, but.

we note that there was reduced occupancy during the time of these measurements due to COVID-19-related restrictions.

As an example of actionable information that was obtained, overnight (10:00 p.m. - 2:00 a.m.) $\mathrm{CO}_{2}$ buildup was observed in classrooms and practice rooms in the music building when the rooms were used informally as practice spaces after hours (Fig. 11b). The ventilation operation for that building was initially set up based on anticipated classroom usage to run only from 5:30 a.m. until 6:00 p.m. and was off at nights and on weekends. Fig. 12a shows data from one music classroom over a two-week period as an example of the high $\mathrm{CO}_{2}$ concentrations, overnight buildup in $\mathrm{CO}_{2}$, and slow decay rates frequently observed. After the data was shared with the facilities managers, the HVAC schedule was updated to include ventilation after hours. This is important if the space is being occupied after hours. $\mathrm{CO}_{2}$ levels at night fell dramatically to where only $<10 \%$ of measurements were $>600 \mathrm{ppm}$ (Fig. 12b), and variability in $\mathrm{CO}_{2}$ concentration decreased. A time-series of $\mathrm{CO}_{2}$ concentration following schedule optimization shows the 


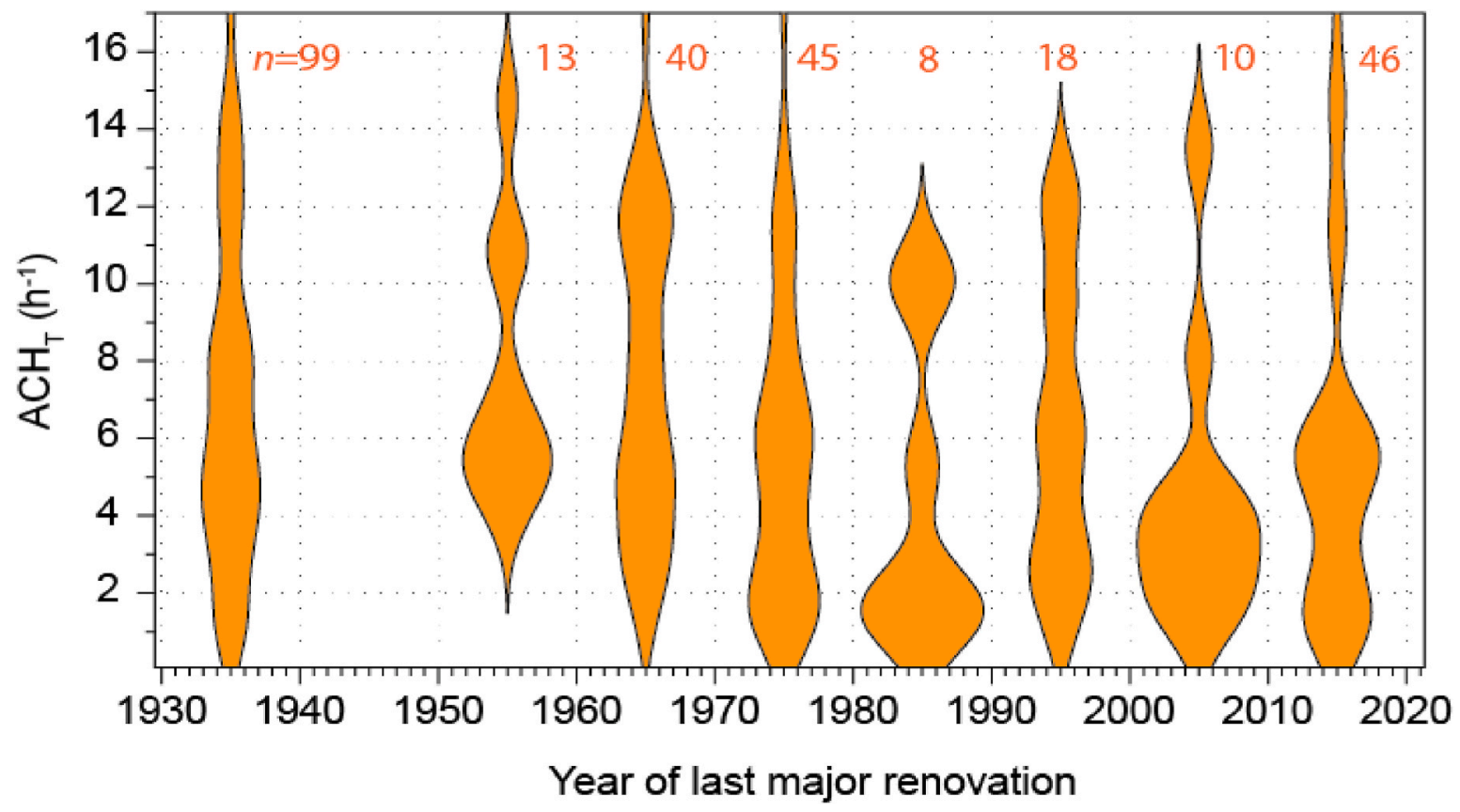

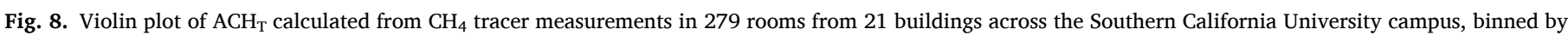

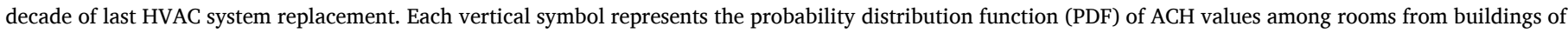

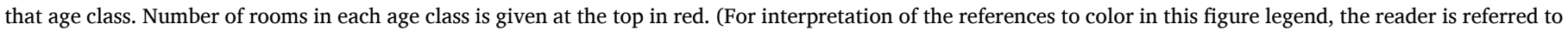
the Web version of this article.)

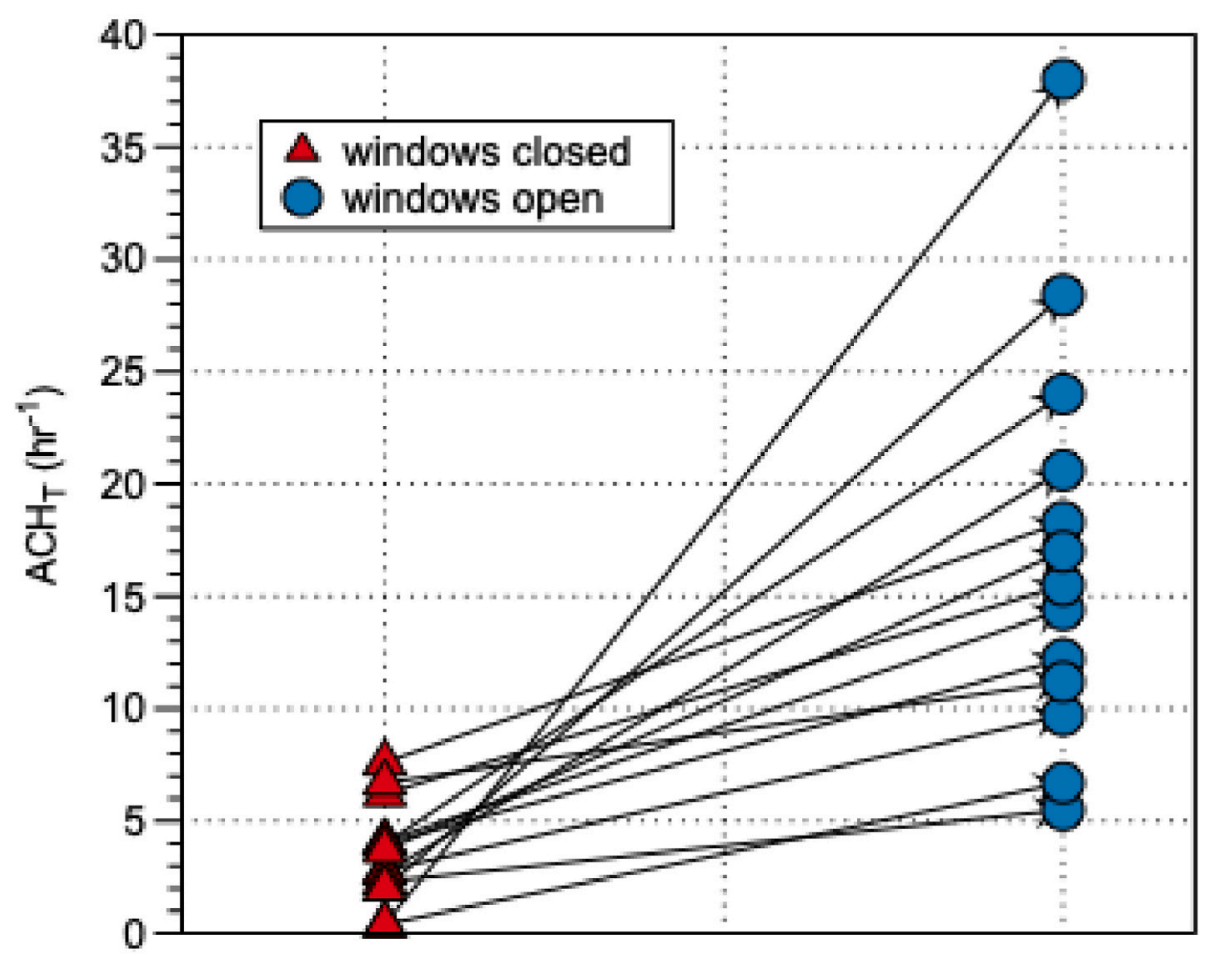

Fig. 9. Comparison of measured outside-air ventilation rates for 11 classrooms and offices in the Southern California Secondary School with windows closed, HVAC on (triangles) versus with windows open (circles).

average $\mathrm{CO}_{2}$ concentration dropped from $741 \pm 105$ ppm to $517 \pm 43$ ppm.

As the above example illustrates, the usage of passive $\mathrm{CO}_{2}$ devices provides a relatively simple, inexpensive, and low-maintenance way to monitor ventilation or changes in space usage, that allows facility managers to make critical updates to ventilation schedules based on real usage data. Observations in the gym complex provided (Fig. S1) a complementary example to the music building scenario, in which passive $\mathrm{CO}_{2}$ monitoring revealed trends in space usage and confirmed the suitability of the ventilation schedule for that facility. See Supporting Information for more details.

A single PM sensor (QuantAQ MODULAIR-PM) was also 


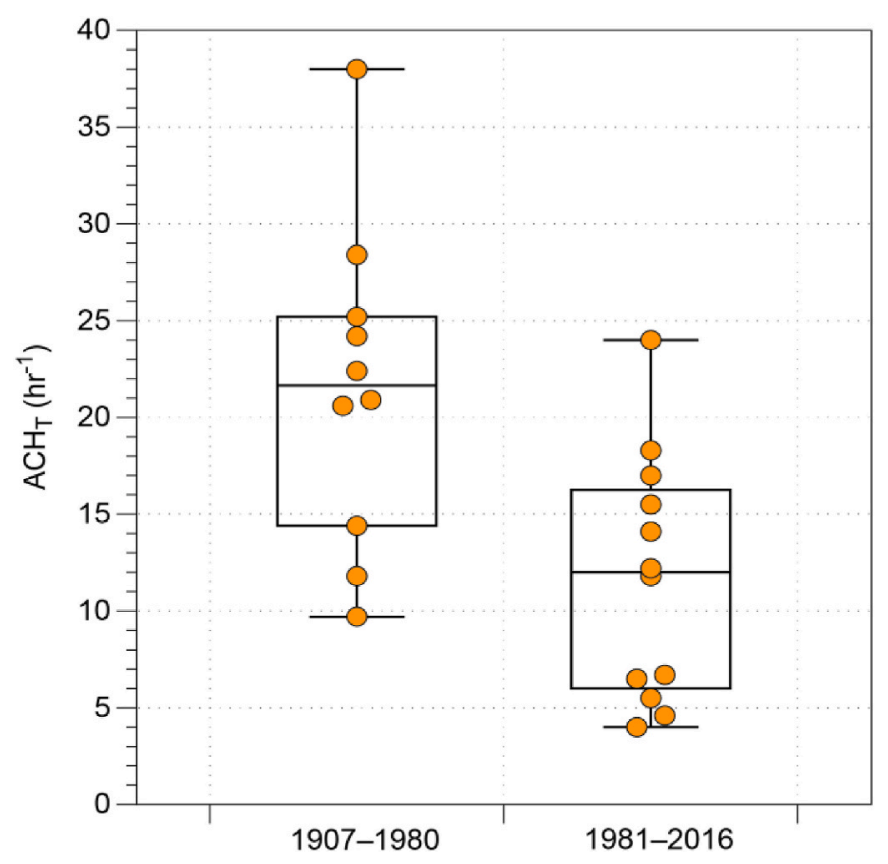

Fig. 10. Summary of ventilation test results for 22 classrooms and offices of the Southern California Secondary School, binned by year of construction. All spaces were tested with windows open using the $\mathrm{CH}_{4}$ controlledrelease method.

continuously operated to passively monitor particulate concentrations in one private music practice room where $\mathrm{CO}_{2}$ device was also installed for passive monitoring. Over a six-month measurement period of November-April, $\mathrm{CO}_{2}$ and PM1 concentrations were compared on an hourly basis and are shown in Supplemental Fig. S2. The time series of $\mathrm{CO}_{2}$ and $\mathrm{PM}_{1}$ values (Fig. S2a) show only mild and inconsistent similarity, and a direct correlation plot (Fig. S2b) shows an extremely low $\mathrm{R}^{2}$ value of $<0.1$. Correlations with $\mathrm{PM}_{2.5}$ and $\mathrm{PM}_{10}$ are similarly poor, but are not shown. As expected, these two pollutants are not related as there are many other sources of particulate matter indoors that do not also emit $\mathrm{CO}_{2}$. In some cases $\mathrm{CO}_{2}$ concentrations are high and PM is relatively lower, and in other cases the opposite is true. These data illustrate that in situ PM monitoring alone, or in combination with $\mathrm{CO}_{2}$ monitoring, cannot easily provide information about the risk of transmission of airborne pathogens in an indoor space, due to the low contribution of respiratory-generated particles or aerosol-borne pathogens to the overall aerosol burden.

3.6 South East University. Professional grade low-cost sensors (QuantAQ MODULAIR-PM and MODULAIR) with the capability to detect carbon dioxide $\left(\mathrm{CO}_{2}\right)$ and particulate matter $(\mathrm{PM})$ were deployed to monitor these species and characterize ventilation rate in various classrooms and indoor spaces at a university in the urban Southeast U.S. from August 2020 through March 2021. The MODULAIR-PM sensor measures PM through a combination of an optical particle counter (OPC) and nephelometer. Similar to Mountain West University, poor correlation was observed between simultaneous in situ $\mathrm{CO}_{2}$ and PM measurements. Buildings studied were built from 1920 to 2020 and have mechanical or natural ventilation systems. Portable HEPA filter-based air cleaners were added as a mitigation to rooms with older mechanical ventilation systems (prior to 1960s). As discussed in the Methodology section, we took advantage of in-person classes and fogging events that occurred when a room was disinfected with a cleaning aerosol spray to calculate $\mathrm{ACH}_{\mathrm{T}}$. In-person classes led to a buildup of $\mathrm{CO}_{2}$ in the room, while fogging released PM. It was ensured that fogging was conducted when no one was in the classroom, and that the personnel performing the fogging were wearing appropriate personal protective gear. In our calculations, it is assumed that the room is well mixed, the only sources of $\mathrm{CO}_{2}$ during classroom occupancy are the occupants, and the only source of PM during the fogging event is the fogging spray. When using PM data to estimate ventilation rate, it is assumed that the effects of aerosol deposition and gravitational settling on aerosol decay rate are negligible. Thus, the calculated ventilation rate based on PM decay analysis may be an overestimation.

Data from two selected classrooms were presented in Fig. 2 of the Methodology section as examples of the technique. Room A is a large lecture hall that is equipped with an HVAC system recirculating indoor air and new outdoor air. The mixture of recirculated and outdoor air is filtered by a MERV 13 filter. Room B is a smaller 20-person classroom that is equipped with an older HVAC system and has a mix of recirculated and outdoor air that is filtered by a MERV 8 filter. Room $B$ also has an added portable air cleaner with a HEPA filter. In these two rooms, background indoor $\mathrm{CO}_{2}$ levels ranged from 350 to $450 \mathrm{ppm}$, and $\mathrm{CO}_{2}$ levels during in-person classes averaged from 430 to $600 \mathrm{ppm}$, occasionally reaching $1000 \mathrm{ppm}$. Background $\mathrm{PM}_{2.5}$ levels ranged from 1 to $10 \mu \mathrm{g} \mathrm{m}^{-3}$ in general, with occasional levels up to $20 \mu \mathrm{g} \mathrm{m}^{-3}$, while fogging events resulted in $\mathrm{PM}_{2.5}$ levels of $40-80 \mu \mathrm{g} \mathrm{m}{ }^{-3}$. The primary filtration of air in Room B is due to the portable air cleaner, which can provide an $\mathrm{ACH}$ of up to $4 \mathrm{~h}^{-1}$ at the maximum setting. Using the decay of $\mathrm{PM}_{2.5}$, the ACH for was estimated to be $2.8 \mathrm{~h}^{-1}$. This indicates that the unit was likely not running at the maximum setting during the fogging event.

Fig. 13 shows a summary of $\mathrm{ACH}_{\mathrm{T}}$ calculated from $\mathrm{CO}_{2}$ decay data in six different classrooms in six buildings across campus over a 2-week period in March 2021. Data are also shown for ACH calculated from the HVAC air supply rates that were available. It is important to note that the ACH values estimated from HVAC flow rates are based on total air flow to the room, which is a mixture of outdoor air ("clean" air) and air recirculated from other rooms (that may contain higher levels of $\mathrm{CO}_{2}$ from occupancy.) Although during the sampling period there were low building occupancy levels due to COVID-19 restrictions, the ACH estimated from HVAC supply flow could be an overestimate of clean air changes. ACH calculated using the air supply was similar to the measured $\mathrm{ACH}_{\mathrm{T}}$ in each case, suggesting that there is no significant interference from recirculated $\mathrm{CO}_{2}$. Overall, the absolute $\mathrm{ACH}$ values found across all buildings were on a similar order of.

magnitude, regardless of building age or type of ventilation (mechanical vs natural). The one exception is the room in building 5 , which saw significantly lower ACH values. This observation was in agreement with building 5 having one of the older HVAC systems on campus, and for these reasons that classroom was equipped with an additional portable HEPA filter air cleaner prior to the beginning of the semester. Unlike the observation by North East University A, the $\mathrm{ACH}_{\mathrm{T}}$ for the naturally ventilated classroom was on the higher end of the range of mechanically ventilated room $\mathrm{ACH}_{\mathrm{T}}$ values, despite being much older than the other buildings investigated. Similar to what Southern California Secondary School noted, this can be attributed to the fact that building 6 is a small classroom with multiple windows. In contrast, buildings $1-5$ have no windows, appear more tightly sealed, and run with mechanical ventilation systems. This is common in both the Southeast U.S. (due to high humidity and heat) and in large university buildings in order to combat high energy expenditures.

In addition to structure and ventilation design, the rooms studied in buildings $1-5$ are centrally located in the building layout. These factors, combined with the fact that buildings $3-5$ have older ventilation systems, could partly explain why observed ACH values were lower than those reported by some of the other universities. It should also be noted that during the sample period, ventilation rates were not at their maximum levels. The rooms in buildings 1 and 2 have $\mathrm{CO}_{2}$ demandcontrolled ventilation, meaning that once $\mathrm{CO}_{2}$ levels reach a certain value (often $800-1000 \mathrm{ppm}$ ) the HVAC system will automatically increase air flow rates. During the time period that these samples were collected, classroom occupancy was limited due to COVID-19 precautions and $\mathrm{CO}_{2}$ levels did not exceed $750 \mathrm{ppm}$ in either room. It is 

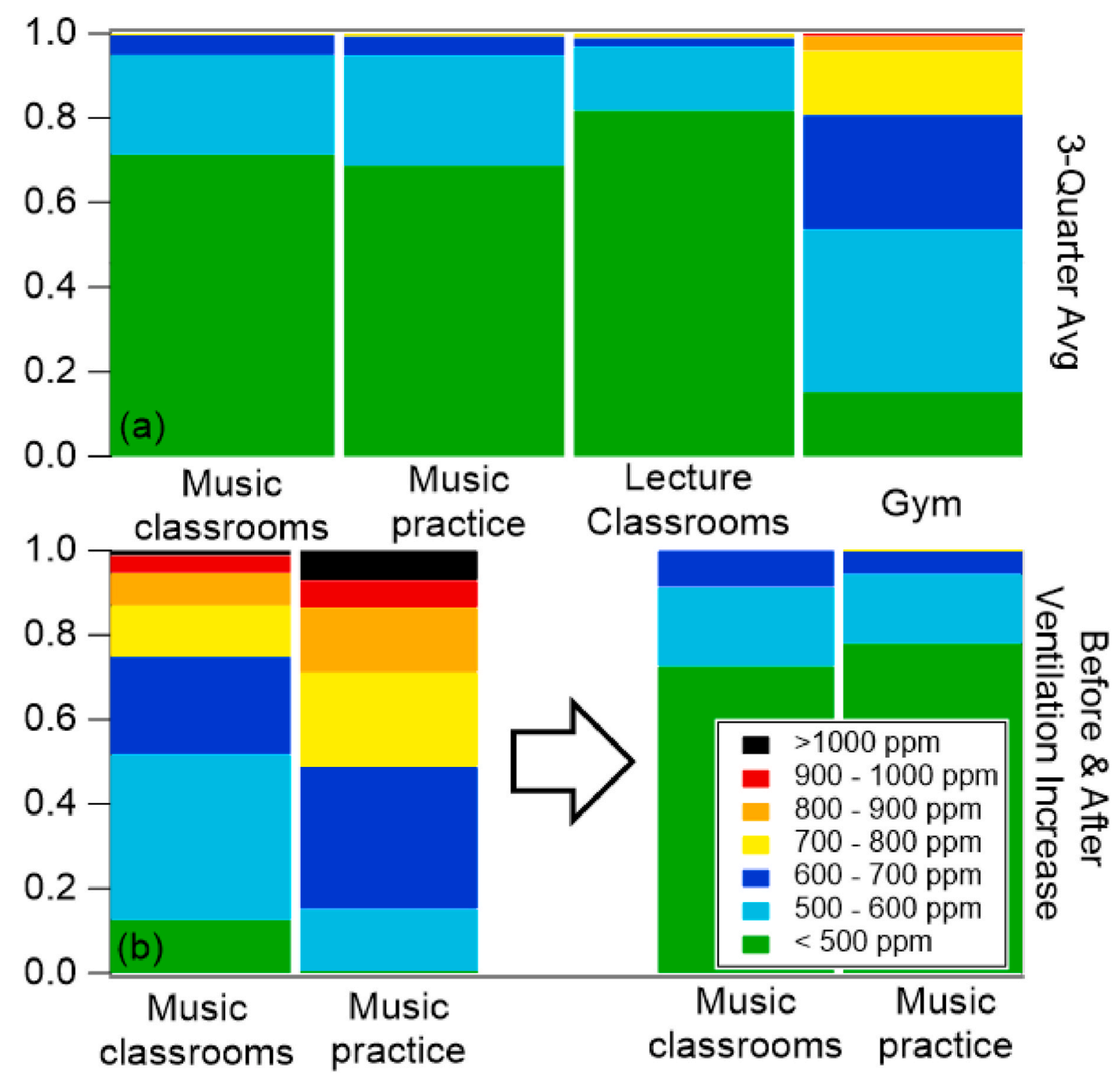

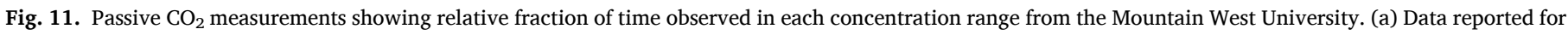

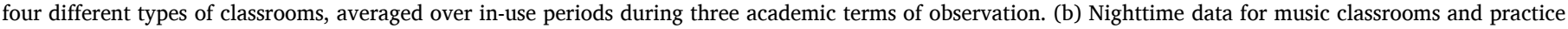

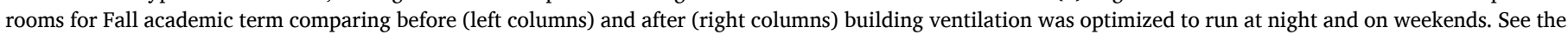
text for additional details of the averaging periods.

possible that higher $\mathrm{CO}_{2}$ levels would result in higher $\mathrm{ACH}_{\mathrm{T}}$ values.

3.7 North East University B. Similar to North East University A, North East University B is situated in an urban area, and comprises buildings with a range of ages and ventilation types. To address the challenges of increasing ventilation and filtration in campus spaces without mechanical ventilation or limited supply, we explored the impact of two portable air cleaner devices on air change rate, and the spatial variation in PM concentrations in a naturally ventilated space, via controlled release of particulate matter. The two air cleaner devices were: (a) a commercially available HEPA recirculating air cleaner (Model HPA 304, Honeywell, Charlotte, NC) as well as (b) an in-house designed and fabricated unit known as the Air Filtering Ventilation Unit (AFVU), which brings in some outdoor air, tempers with a return, and includes MERV 14 filtration, effectively simulating a typical mechanical ventilation system (Fig. S3, see Supporting Information for more details).

A library space on campus with no mechanical ventilation, was used for testing as it was representative of other classroom spaces and common rooms on campus. Additional details of the testing space are given in the Supplemental Information. The room was pre-cleaned by HEPA filtered vacuuming and damp wiping of hard surfaces, and a sticky mat was placed at the room entryway. Radiator blower fans were turned "off" during testing. In addition, all windows, fireplaces, passive air transfer grilles, built-in wall bookcases, radiator covers, and floor rugs were covered with polyethylene sheeting and taped shut. As testing was conducted in January 2021 with lower humidity levels (19-22\%), all polyethylene sheets used in the space were electrically grounded by bonding with aluminum metal tape and copper wire to metal outlet covers to help reduce static electricity. The commercial air cleaner was operated in two modes ( $80 \mathrm{CFM}$ and $320 \mathrm{CFM}$ ) and was positioned in the center of the room, $0.6 \mathrm{~m}$ away from one of the 4 sampling locations (S1, Fig. 14). Details of the AFVU placement and operation can be found in the Supporting Information.

Test PM was generated using fog generators (Model C Breeze, Degree Controls, Inc., Milford, NH) with long-duration fog liquid. Paraffin candles ("Glimma", Ikea Systems, BV, Sweden) were also used to generate test PM. PM levels $(0.02-1.0 \mu \mathrm{m})$ were monitored in real-time using a P-Trak monitor (Model 8525, TSI, Shoreview, MN). Four P-Trak 


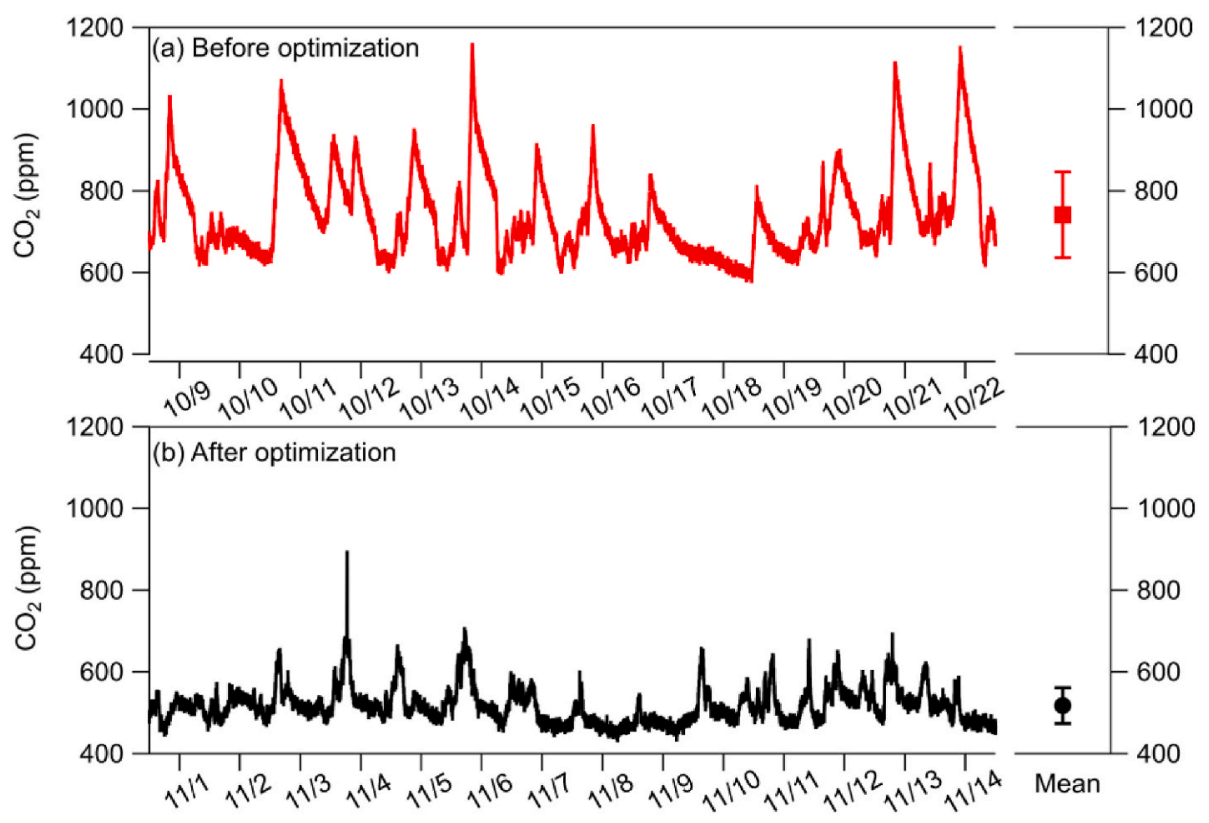

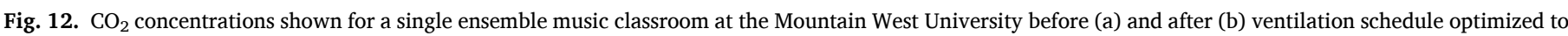
run also at nights and on weekends. Mean value shown for two-week window displayed in each case, where bars show standard deviation of measurements.

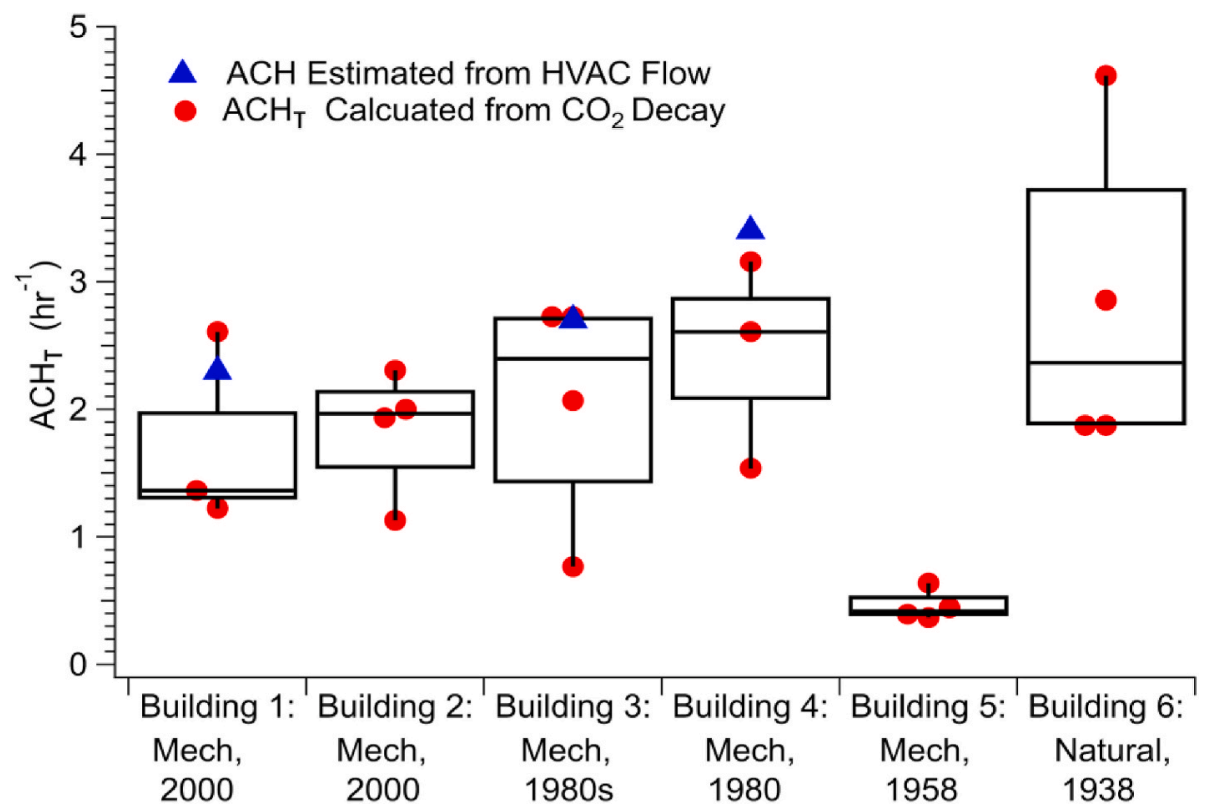

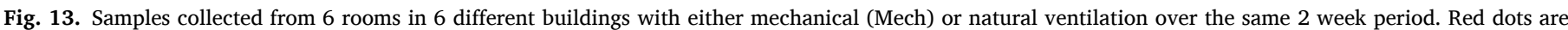

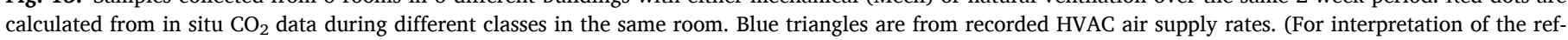
erences to color in this figure legend, the reader is referred to the Web version of this article.)

monitors were positioned at different locations across the testing space and operated in parallel. Temperature and humidity (Model EVM, 3M, Oconomowoc, WI) was also continuously monitored at the approximate room center.

In the first set of experiments, we used the controlled release of PM to evaluate the air change rate provided by each of the portable air cleaner devices. This procedure was modified from one developed by the Association of Home Appliance Manufacturers (AHAM) for testing portable air cleaning devices inside a sealed laboratory chamber, but here we use a real-life space with less.

controlled conditions and a different PM source. In this set of experiments we released PM from two foggers, which were oriented facing the center of the room, positioned $1 \mathrm{~m}$ from opposite walls, and $1 \mathrm{~m}$ above the ground (Fig. 14). The generated PM was dispersed in the room using two box fans (Model 9723, AirKing, Inc., West Chester, PA) for 1 min. These box fans were positioned under the fogger devices. The foggers were then shut off, room air mixing continued for one additional minute with the box fans, and particle concentrations monitored for 10 min, at which time four recirculating HEPA-filtered blowers (Model Defendair HEPA 500, Sylvane, Inc., Roswell, GA) were turned on to clean room air in preparation for the next test. Natural particle removal (decay) rates were measured this way under static room conditions without any ventilation or air cleaning equipment running. The effectiveness of the AFVU and the commercially available HEPA air cleaner 

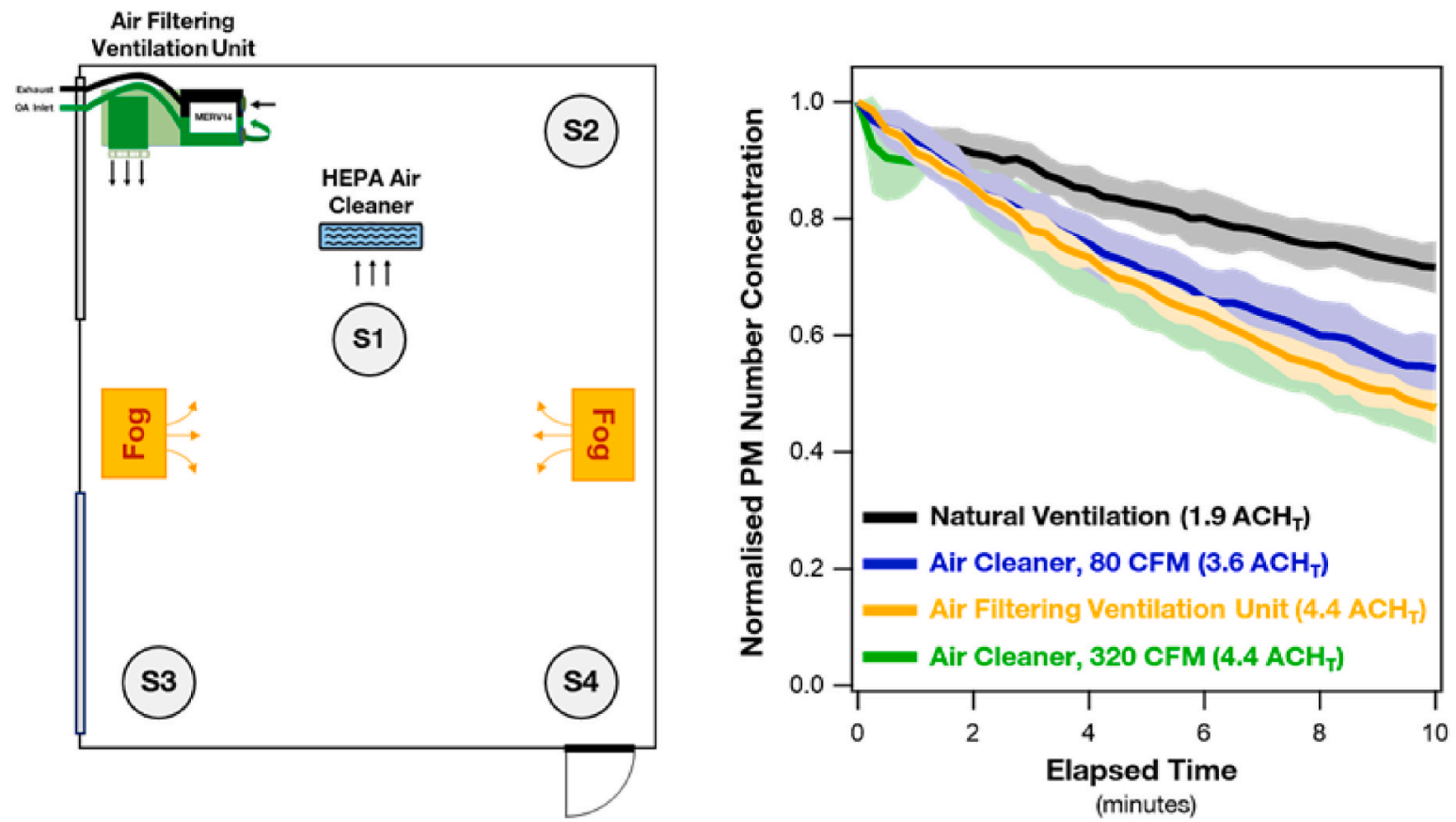

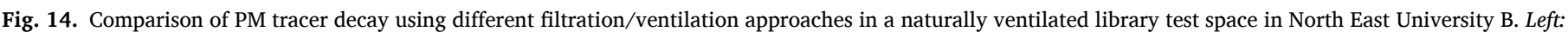

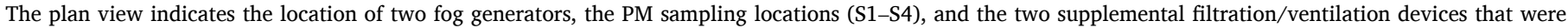

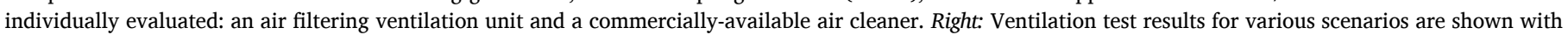
the measured $\mathrm{ACH}_{\mathrm{T}}$.

were assessed individually by turning each unit on once the fog release and air mixing were completed, and the rate of aerosol removal was compared to the natural decay rate. PM decay was assessed at each of the four sampling locations; the mean and associated standard deviation are shown Fig. 14. The AFVU and the commercially available portable air cleaner both enhanced $\mathrm{ACH}_{\mathrm{T}}$ compared to natural ventilation in the test space (1.9 per hour). Operation of the commercial filtration unit at the low fan speed $(80 \mathrm{CFM})$ provided $3.6 \mathrm{ACH}_{\mathrm{T}}$. Increasing the flow of this unit to $320 \mathrm{CFM}$ achieved a similar $\mathrm{ACH}_{\mathrm{T}}$ as the AFVU 4.4 per hour.

We also evaluated the spatial distribution of aerosol across the test space using the two supplemental filtration/ventilation approaches (see Supporting Information). When a continuous PM source was provided via burning candles in the center of the test space, use of the commercial HEPA recirculating filter resulted in more spatial heterogeneity than the AFVU, with high stable PM concentrations found over the entire test period at sampling locations S1 and S3 (Fig. S4). This was attributable to

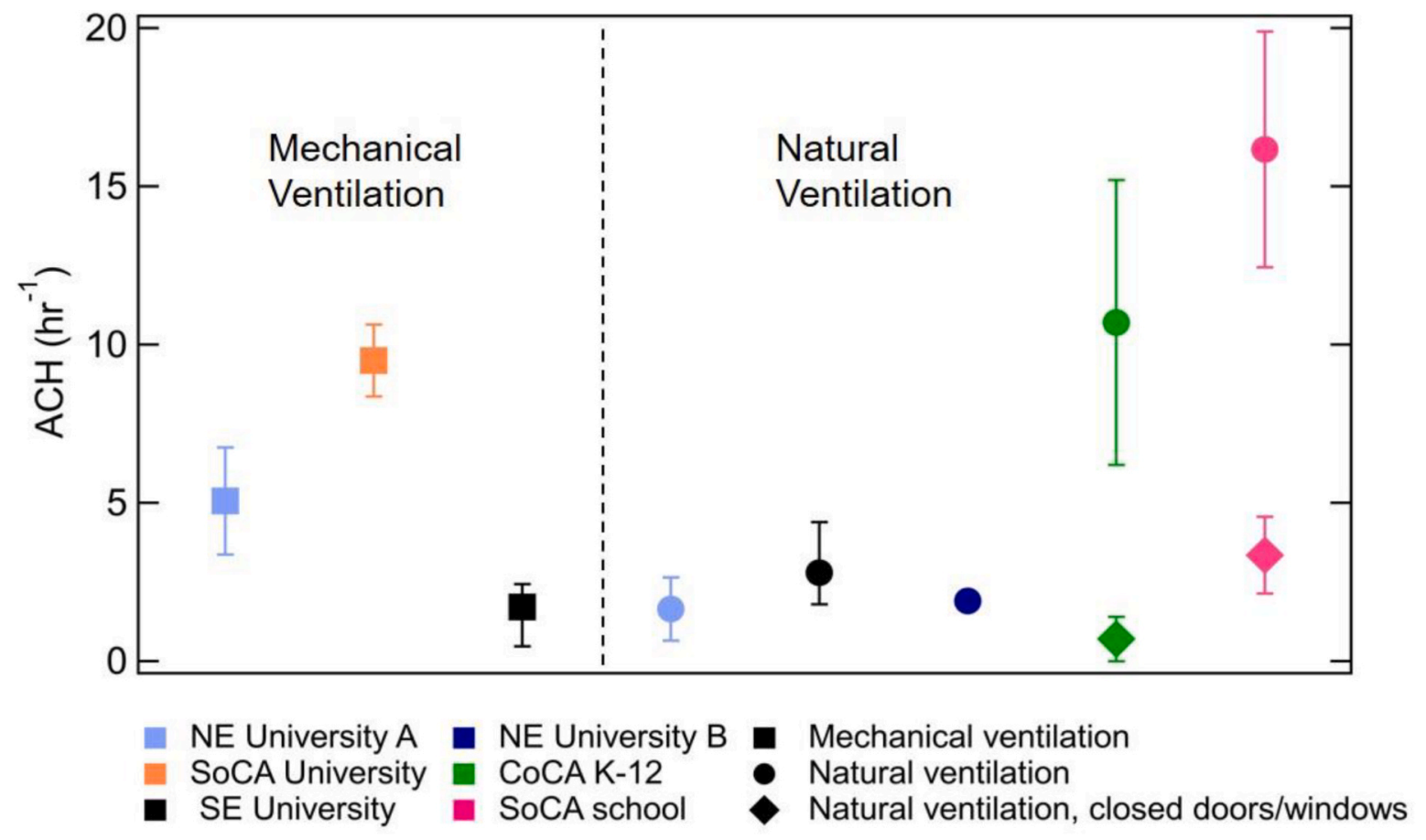

Fig. 15. Summary of ventilation measurements reported here. NE: North East, SE: South East, CoCA: Coastal California, SoCA: Southern California. 
the poor mixing of vertical discharge under dynamic continuous PM generation for the ventilation conditions of the room and lower airflow rate compared to the AFVU. Details may be found in the Supporting Information.

Overall, the mid-sized recirculating HEPA-filtered air cleaner improved $\mathrm{ACH}_{\mathrm{T}}$ in the naturally ventilated library. The highest fan speed of the commercial device achieved an equivalent total ACH as the AFVU that provides $20 \%$ outdoor air. The AFVU, however, provided improved $\mathrm{PM}$ removal rates across the test space compared to the commercial unit when tested against continuously generated PM that might occur in an occupied room. We concluded based on these studies that deployment of the two tested portable air cleaners in spaces without mechanical ventilation on campus could be used to improve indoor air quality, aligning spaces with applicable ventilation guidelines and support increases in room occupancy rates.

\section{Discussion}

Fig. 15 summarizes the ACH measurements made at the different institutions in this study.

The naturally ventilated buildings on the West Coast studied here were designed for cross-ventilation and had relatively high $\mathrm{ACH}$, particularly when windows and exterior doors were opened, consistent with previous findings (Howard-Reed et al., 2002). In each case, cross-ventilation with open windows and/or doors led to higher ventilation rates than sealing the room and using HVAC. For the buildings studied in Southern California, older construction corresponded to better ventilation.

Older buildings in the Northeast U.S. without mechanical ventilation, designed to keep heat in during cold winters, often have insufficient air exchange. Many buildings in the Northeast were designed in the wake of the 1918 influenza pandemic for windows to be open yearround, even while a steam radiator was in operation during winter (Sisson, 2020). This practice has fallen out of favor over the past century as energy efficiency became a priority. Given the relatively low cost of portable filter-based air cleaners, their installation in buildings of this type may be justified even when ventilation data are not available for these spaces, or measurements are not practical.

We note that, for both naturally and mechanically ventilated systems, ventilation parameters and airflow patterns vary with occupancy and ambient weather conditions or season. Measurements should ideally be made for a variety of conditions to get a more comprehensive picture of ventilation for a particular space.

The controlled-release experiments described here were effective for characterizing ventilation in a mixture of building types encountered in U.S. universities and K-12 schools in a repeatable manner. While all the approaches discussed here yielded valuable insights, those employing low cost, reliable, easy-to-use sensors are best suited to general use. Other approaches employed costly equipment or required specialized technical expertise to perform the experiments or interpret the data.

At North East University B, controlled-release PM experiments allowed estimation of air change rates and revealed spatial variation in flow patterns in naturally ventilated rooms. Those results, along with the observations of delayed clearance in sections of some irregularly shaped classrooms in the Coastal California K-12 School District (Fig. 6), highlight that a room-level evaluation of ventilation may mask heterogeneity in flow fields and potentially problematic microenvironments within an otherwise well-ventilated room. The effectiveness of this approach relies on the use of very fine particles that have minimal additional removal process such as deposition to surfaces. In situ monitoring of absolute PM concentrations is fundamentally limited as an indicator of aerosol pathogen risk, however, because the concentration of PM associated with respiratory emissions of infected individuals will generally be small compared to background aerosol.

$\mathrm{CO}_{2}$ controlled-release experiments, such as were performed at North East University A and Coastal California K-12 School District, are most effective for naturally ventilated buildings or during periods of low occupancy in mechanically ventilated buildings, due to the risk of interference from recirculated $\mathrm{CO}_{2}$. For the studies presented here, which were conducted in Summer-Fall 2020) and early 2021, low occupancy was the norm due to COVID-19 related occupancy restrictions, but similar conditions may be encountered after hours or during holidays.

In situ monitoring is an accessible approach for observing air quality trends while a space is being actively used, allowing quick response once problems are identified, in the form of schedule changes or engineering interventions. Setup and maintenance of low-cost sensors for $\mathrm{CO}_{2}$ or PM requires relatively little technical expertise.

\section{Conclusion}

Ventilation and filtration are key components of a layered approach towards risk reduction for the transmission of airborne infectious diseases. Such an approach also includes vaccines, masking, physical distancing and other controls on occupancy, and testing. Adequate ventilation and air cleaning is also critical for maintaining healthy indoor air quality.

We have presented a number of practical approaches for gathering room-level ventilation data for educational spaces, and anecdotal examples of their application in a range of building and room types, and climates across the U.S. In particular, approaches using reliable low-cost air quality sensors show promise for use by nonspecialists. Room-level ventilation data allows consideration of indoor air quality and transmission of respiratory disease in decision making with regards to occupancy and ventilation strategies. As we have demonstrated, it can also be critical in identifying areas for mitigation (i.e. with filtration devices) and providing clues into building occupancy patterns which must be accounted for in the ventilation strategy.

Ventilation data can also be useful for communicating and building trust with faculty, staff, students, and the rest of the community. Knowing that ventilation is satisfactory, problem areas have been identified, and mitigation measures have been put into place can ease anxieties and build confidence about return to campus or increased occupancy, and improve confidence in the future indoor air quality. Broad participation in the process of data collection, made possible by the use of more accessible approaches such as in situ $\mathrm{CO}_{2}$ monitoring with low cost sensors, can provide an additional sense of agency (Schaefer et al., 2020).

\section{Author contributions}

VFM, JAH, DYM, NLN, KJGP, RS, AS, TS, and SW designed experiments, analyzed and interpreted data. JAH, DYM, NLN, KJGP, RS, AS, TS, and SW collected data. All authors participated in writing the manuscript and the development of Table 1.

\section{Declaration of competing interest}

The authors declare that they have no known competing financial interests or personal relationships that could have appeared to influence the work reported in this paper.

\section{Acknowledgements}

The authors thank Prof. Bill Nazaroff and Prof. Atila Novoselac for helpful discussions. VFM and DYM acknowledge Columbia University School of Engineering and Applied Sciences and the Alfred P. Sloan Foundation Chemistry of Indoor Environments program for financial support, and Columbia Facilities. TMS and RAS gratefully acknowledge the Santa Barbara Unified School District and Goleta Union School District for their cooperation and help with measurements. ALS acknowledges Caltech and the Divisions of Geological \& Planetary 
Sciences and Chemistry and Chemical Engineering for financial support, Caltech Facilities for testing and data collection, and Nathan Dalleska, John Crounse, and Paul Wennberg for contributions to method development and deployment. SW and NLN acknowledge support from Georgia Tech COVID-19 Rapid Response fund, and helpful discussions with Philip Johnston, Richard Chew, and Gregory Spiro from Georgia Tech Facilities. JAH acknowledges the University of Denver COVID-19 Response team, Department of Facilities Management, Lamont School of Music, and Planning, and Office of the Provost for funding and support. CK, RK, ML, and KJGP acknowledge the support of Julie Paquette, Anthony Kosior, and JP Fernandez with method development and deployment. PJO acknowledges support from the Johns Hopkins Center for Health Security and the Open Philanthropy Project.

\section{Appendix A. Supplementary data}

Supplementary data to this article can be found online at https://doi. org/10.1016/j.aeaoa.2022.100152.

\section{References}

ASHRAE, 2017. Standard Project Committee 170, ANSI/ASHRAE Standard 111-2008 (RA 2017), Measurement, Testing, Adjusting, and Balancing of Building HVAC Systems.

ASHRAE, 2019. Standing Standard Project Committee 62.1, ANSI/ASHRAE Standard 62.1-2019, Ventilation for Acceptable Indoor Air Quality.

ASHRAE Epidemic Task Force. Core recommendations for reducing airborne infections aerosol exposure. https://www.ashrae.org/file\%20library/technical\% 20resources/covid-19/core-recommendations-for-reducing-airborne-infectiousaerosol-exposure.pdf January 2021.

Batterman, S., 2017. Review and extension of $\mathrm{CO}_{2}$-based methods to determine ventilation rates with application to school classrooms. Int. J. Environ. Res. Publ. Health 14 (2), 145.

Bhangar, S., Huffman, J.A., Nazaroff, W.M., 2014. Size-resolved fluorescent biological aerosol particle concentrations and occupant emissions in a university classroom. Indoor Air 24 (6), 604-617. https://doi.org/10.1111/ina.12111.

Centers for Disease Control and Prevention. National center for immunization and respiratory diseases. FLUVIEW: A Weekly Influenza Surveillance Report Prepared by the Influenza Division. https://www.cdc.gov/flu/weekly/weeklyarchives2020-202 1/ILI22.html. (Accessed August 2021).

Charlesworth, P.S., August 1988. International Energy Agency: Air Infiltration and Ventilation Centre. In: Air exchange rate and airtightness measurement techniques an applications guide. Oscar Faber, St Albans.

Corsi, R., Miller, S.L., VanRy, M.G., Marr, L.C., Cadet, L.R., Pollock, N.R., Michaels, D., Jones, E.R., Levinson, M., Li, Y., Morawska, L., Macomber, J., Allen, J.G. Designing infectious disease resilience into school buildings through improvements to ventilation and air cleaning. reportReport of the Lancet COVID-19 Commission Task Force on Safe Work, Safe School, and Safe Travel https://covid19commission.org/ safe-work-travel April 2021.

Fisk, W.J., 2017. The ventilation problem in schools: literature review. Indoor Air 27 (6), 1039-1051.

Gettings, J., Czarnik, M., Morris, E., Haller, E., Thompson-Paul, A.M., Rasberry, C., Lanzieri, T.M., Smith-Grant, J., Aholou, T.M., Thomas, E., Dreznek, C., KacKellar, D., 2021. Mask use and ventilation improvements to reduce COVID-19 incidence in elementary schools - Georgia, november 16-december 11, 2020. MMWR Morb. Mortal. Wkly. Rep. 70, 779-784. https://doi.org/10.15585/mmwr.mm7021e1.

Green Buildings Council, U.S., LEED, B.D.+C., 2019. New Construction V4 Minimum Indoor Air Quality Performance. https://www.usgbc.org/credits/new-construction /v4-draft/eqp1.
Greenhalgh, T., Jimenez, J.L., Prather, K.A., Tufekci, Z., Fisman, D., Schooley, R., 2021. Ten scientific reasons in support of airborne transmission of SARS-CoV-2. Lancet 397, 1603-1605. https://doi.org/10.1016/S0140-6736(21)00869-2, 10285.

Howard-Reed, C., Wallace, L.A., Ott, W.R., 2002. The effect of opening windows on air change rates in two homes. J. Air Waste Manag. Assoc. 52 (2), 147-159. https://doi. org/10.1080/10473289.2002.10470775.

Jones, E., Young, A., Clevenger, K., Salimifard, P., Wu, E., Lahaie Luna, M., Lahvis, M., Lang, J., Bliss, M., Azimi, P., Cedeno-Laurent, J., Wilson, C., Segule, M.N., Keshavarz, Z., Chin, W., Dedesko, S., Parikh, S., Vallarino, J., Allen, J., 2020. Healthy Schools: Risk Reduction Strategies for Reopening Schools. Harvard T.H. Chan School of Public Health Healthy Buildings program, November.

Korsavi, S.S., Montazami, A., Mumovic, D., 2020. Ventilation rates in naturally ventilated primary schools in the UK; Contextual, Occupant and Building-related (COB) factors. Build. Environ. 181, 107061.

Lednicky, J.A., Lauzardo, M., Fan, Z.H., Jutla, A., Tilly, T.B., Gangwar, M., Usmani, M., Shankar, S.N., Mohamed, K., Eiguren-Fernandez, A., Stephenson, C.J., Alam, M.M., Elbadry, M.A., Loeb, J.C., Subramaniam, K., Waltzek, T.B., Cherabuddi, K., Morris, J. G., Wu, C.-Y., 2020. Viable SARS-CoV-2 in the air of a hospital room with COVID-19 patients. Int. J. Infect. Dis. 100, 476-482. https://doi.org/10.1016/j. ijid.2020.09.025.

Levinson, M., Geller, A.C., Allen, J.G., 2021. The lancet COVID-19 commission task force on safe work, safe school, and safe travel. Health equity, schooling hesitancy, and the social determinants of learning. Lancet Reg. Health - Americas 2, 100032. https:// doi.org/10.1016/j.lana.2021.100032.

Li, Y., Leung, G.M., Tang, J.W., Yang, X., Chao, C.Y., Lin, J.Z., Lu, J.W., Nielsen, P.V., Niu, J., Qian, H., Sleigh, A.C., Su, H.J., Sundell, J., Wong, T.W., Yuen, P.L., 2007. Role of ventilation in airborne transmission of infectious agents in the built environment - a multidisciplinary systematic review. Indoor Air 17 (1), 2-18. https://doi.org/10.1111/j.1600-0668.2006.00445.x.

Miller, S.L., Nazaroff, W.M., Jimenez, J.L., Boerstra, A., Buonanno, G., Dancer, S.J. Kurnitski, J., Marr, L.C., Morawska, L., Noakes, C., 2021. Transmission of SARS-CoV2 by inhalation of respiratory aerosol in the Skagit Valley Chorale superspreading event. Indoor Air 31 (2), 314-323. https://doi.org/10.1111/ina.12751.

NOAA Global Monitoring Laboratory. Trends in atmospheric carbon dioxide. https ://www.esrl.noaa.gov/gmd/ccgg/trends/mlo.html. (Accessed August 2021).

Peng, Z., Jimenez, J.L., 2021. Exhaled $\mathrm{CO}_{2}$ as a COVID-19 infection risk proxy for different indoor Environments and activities. Environ. Sci. Technol. Lett. 8 (5), 392-397. https://doi.org/10.1021/acs.estlett.1c00183.

Persily, A., February 1988. Tracer Gas Techniques for Studying Building Air Exchange. United States National Bureau of Standards NBSIR, 88-3708.

Persily, A.K., 2016. Field measurement of ventilation rates. Indoor Air 26, 97-111. https://doi.org/10.1111/ina.12193.

Rudnick, S.N., Milton, D.K., 2003. Risk of indoor airborne infection transmission estimated from carbon dioxide concentration. Indoor Air 13 (3), 237-245. https:// doi.org/10.1034/j.1600-0668.2003.00189.x.

Schaefer, T., Kieslinger, B., Fabian, C.M., 2020. Citizen-based air quality monitoring: the impact on individual citizen scientists and how to leverage the benefits to affect whole regions. Citiz. Sci. Theory Pract. 5 (1), 6. https://doi.org/10.5334/cstp.245, 2020.

Singer, B.C., Delp, W.W., 2018. Response of consumer and research grade indoor air quality monitors to residential sources of fine particles. Indoor Air 28, 624-639. https://doi.org/10.1111/ina.12463.

Sisson, P., Aug 5 2020. Your Old Radiator Is a Pandemic-Fighting Weapon. Bloomberg CityLab. https://www.bloomberg.com/news/articles/2020-08-05/the-curious-his tory-of-steam-heat-and-pandemics.

Tang, M., Zhu, N., Kinney, K., Novoselac, A., 2020. Transport of indoor aerosols to hidden interior spaces. Aerosol. Sci. Technol. 54 (1), 94-110. https://doi.org/ 10.1080/02786826.2019.1677854.

Turner, W.J.N., Sherman, M.H., Walker, I.S., 2012. Infiltration as ventilation: weatherinduced dilution. HVAC R Res. 18 (6), 1122-1135. https://doi.org/10.1080/ 10789669.2012.704836.

Wargocki, P., Porras-Salazar, J.A., Contreras-Espinoza, S., Bahnfleth, W., 2020. The relationships between classroom air quality and children's performance in school. Build. Environ. 173, 106749. https://doi.org/10.1016/j.buildenv.2020.106749. 